\title{
Modelling Competencies for Computing Education beyond 2020: A Research Based Approach to Defining Competencies in the Computing Disciplines
}

\author{
Stephen Frezza \\ Gannon University \\ Erie, PA, USA \\ frezza001@gannon.edu \\ Åsa Cajander \\ Uppsala University \\ Uppsala, Sweden \\ asa.cajander@it.uu.se \\ Roger McDermott \\ The Robert Gordon University \\ Aberdeen, Scotland, UK \\ roger.mcdermott@rgu.ac.uk
}

\author{
Mats Daniels \\ Uppsala University \\ Uppsala, Sweden \\ mats.daniels@it.uu.se \\ Viggo Kann
KTH Royal Institute of Technology
Stockholm, Sweden \\ viggo@kth.se
Anne-Kathrin Peters
Uppsala University
Uppsala, Sweden
anne.peters@it.uu.se \\ Charles Wallace \\ Michigan Tech University \\ Houghton, MI, USA \\ wallace@mtu.edu
}

\author{
Arnold Pears \\ KTH Royal Institute of Technology \\ Stockholm, Sweden \\ pears@kth.se \\ Amanpreet Kapoor \\ University of Florida \\ Gainesville, FL, USA \\ kapooramanpreet@ufl.edu \\ Mihaela Sabin \\ University of New Hampshire \\ Manchester, NH, USA \\ mihaela.sabin@unh.edu
}

\begin{abstract}
How might the content and outcomes of tertiary education programmes be described and analysed in order to understand how they are structured and function? To address this question we develop a framework for modelling graduate competencies linked to tertiary degree programmes in the computing disciplines. While the focus of our work is computing the framework is applicable to education more broadly.

The work presented here draws upon the pioneering curricular document for information technology (IT2017), curricular competency frameworks, other related documents such as the software engineering competency model (SWECOM), the Skills Framework for the Information Age (SFIA), current research in competency models, and elicitation workshop results from recent computing conferences.

The aim is to inform the ongoing Computing Curricula (CC2020) project, an endeavour supported by the Association for Computing Machinery (ACM) and the IEEE Computer Society. We develop the Competency Learning Framework (CoLeaF), providing an internationally relevant tool for describing competencies. We argue that

Permission to make digital or hard copies of all or part of this work for personal or classroom use is granted without fee provided that copies are not made or distributed for profit or commercial advantage and that copies bear this notice and the full citation on the first page. Copyrights for components of this work owned by others than the author(s) must be honored. Abstracting with credit is permitted. To copy otherwise, or republish, to post on servers or to redistribute to lists, requires prior specific permission and/or a fee. Request permissions from permissions@acm.org.

ITiCSE '18 Companion, fuly 2-4, 2018, Larnaca, Cyprus

(C) 2018 Copyright held by the owner/author(s). Publication rights licensed to ACM. ACM ISBN 978-1-4503-6223-8/18/07.

https://doi.org/10.1145/3293881.3295782
\end{abstract}

this competency based approach is well suited for constructing learning environments and assists degree programme architects in dealing with the challenge of developing, describing and including competencies relevant to computer and IT professionals.

In this paper we demonstrate how the CoLeaF competency framework can be applied in practice, and though a series of case studies demonstrate its effectiveness and analytical power as a tool for describing and comparing degree programmes in the international higher education landscape.

\section{CCS CONCEPTS}

- Social and professional topics $\rightarrow$ Computing education;

\section{KEYWORDS}

Computing competencies; Professional competencies; curriculum guidelines; CC2020

\section{ACM Reference Format:}

Stephen Frezza, Mats Daniels, Arnold Pears, Åsa Cajander, Viggo Kann, Amanpreet Kapoor, Roger McDermott, Anne-Kathrin Peters, Mihaela Sabin, and Charles Wallace. 2018. Modelling Competencies for Computing Education beyond 2020: A Research Based Approach to Defining Competencies in the Computing Disciplines. In Proceedings Companion of the 23rd Annual ACM Conference on Innovation and Technology in Computer Science Education (ITiCSE '18 Companion), fuly 2-4, 2018, Larnaca, Cyprus. ACM, New York, NY, USA, 27 pages. https://doi.org/10.1145/3293881.3295782

\section{INTRODUCTION}

John Dewey and his compatriots proposed that a central goal of higher education is "assisting individuals to develop the capacities 
to realise their vocation (i.e., to be effective in their preferred occupation)" [63]. Similarly pragmatic and utilitarian views of higher education were also advanced by other visionaries such as Humboldt, however the focus of his interest was largely in the development of the citizen.

To achieve this goal it is necessary to establish, evolve and assess the educational process by which students in computing degree programs make the transition into becoming computing professionals. Historically, computing education has taken a content knowledge perspective, through the definition of bodies of knowledge and program outcomes that focus on the content knowledge of the degree program [69]. This focus on knowledge is however problematic in the 21st century computing context, where the borders between knowledge-based descriptions of computing sub-disciplines and the broad profession of computing are becoming increasingly blurred. In computing and IT, challenges also emerge due to the complex dependencies inherent in the profound integration of these disciplines into almost every aspect of human life.

This article develops an empirically driven framework (CoLeaF) for defining competencies in the computing disciplines in tertiary education. To develop CoLeaF, we applied a multi-faceted approach which combines a comprehensive synthesis of the literature with structured elicitation of graduate competencies from key stakeholder groups ${ }^{1}$. In particular we explored the student discourse surrounding professional competencies, and the development of conceptions of professional competencies over time. As a theoretical point of departure we examine the literature around the notion of competency as a means to describe and communicate about computing programs among different stakeholders. Drawing upon this analysis we propose a working definition of competency, and model competency learning, through which students develop the competencies of their degree programme.

The aim is to provide a forward looking and sustainable approach to defining disciplinary competencies. We propose a shift in the approach from graduate learning outcomes derived from the Bodies of Knowledge (BoK) of the disciplinary areas. Instead, we propose applying a structured analysis to graduate expectations elicited from the stakeholders in computing education. These stakeholders include educators, students, industry and other employers of computing graduates, policy makers, professional societies, etc. To assist in the derivation of competencies that articulate expectations of graduates from tertiary computing degree programs as they enter professional careers and engage in civic aspects of their lives, we propose a theoretical model and methodology for formulating competencies based on input from the range of stakeholder communities we have identified.

Defining a competency-based description of a computing degree program by using the competency model proposed here involves collecting empirical data through surveys and interviews with stakeholders. The data sets are then systematically examined by applying the proposed model and analytic methodology in order to derive a set of competencies, in which increasingly abstract competencies describe computing degree program objectives and graduate profile in terms of what its graduates are prepared to do in the workplace and society at large.

\footnotetext{
${ }^{1}$ This paper was produced as Working Group 6 at ITiCSE 2018, Larnaca, Cyprus.
}

The application of the model is demonstrated on two sets of data collected from academic and student stakeholder groups, which are analysed to formulate competencies that provide a concrete example of how the model and methodology are applied.

\subsection{Motivation}

The educational needs of students in computing evolve in alignment with the development of the intellectual and practical domains that constitute the profession. Among the many issues involved is the emergence of more common understandings of what makes up computing as a discipline, and how computing education is described and communicated among various stakeholders. Answering these questions is critical both for determining what new developments further expand the depth and breadth of the discipline, and those that cross over into other intellectual and professional domains. In computing education, this is particularly important, as there are significant differences with respect to what is meant for a particular computing term in different sub-disciplines of computing, and in the various educational programs around the world. Thus, there is a critical need for a 'common currency' to reasonably describe computing education programs and their respective goals.

Similarly, computing is more accurately described as a family of disciplines, with reliance on three intertwined intellectual traditions: the mathematical (or analytical, theoretical, or formalist) tradition, the scientific (or empirical) tradition, and the engineering (or technological) tradition [98]. Within all three of these intellectual traditions, the common tendency has been to develop competency models and ontologies that focus primarily on cognitive development [48], and hence the prevalence of knowledge dimension. Consequently, one of the motivations for this work is to propose a model and methodology that allow the goals of tertiary degree programs to extend 'beyond the cognitive' $[59,101]$ and be more explicit about articulating the skills, knowledge, attitudes, and professional values expected in a graduate.

A third motivation is to encourage tertiary computing programs to explicitly extend their focus 'beyond the technical'. Numerous professional (e.g., [68]), degree program (e.g., [86]) and disciplinary documents (e.g., [92], [69, 96]) strongly suggest that computing students need to exhibit professional competency in multiple ways beyond their technical knowledge. Broadening the scope of the discipline, for example, by emphasising social aspects, can lead to more diversity in the people engaging in computer science [31, 32], and thus to a more democratic advancement of technological development. In this manner, a compelling competency model offers a means of integrating more explicitly expectations of computing graduates that expand beyond the technical domain.

The normative solution to issues pertaining to meaning is to develop an ontology that creates an agreed-upon structure of language and defines an area for common use, such that this language then becomes the "common currency" for establishing shared meaning. Various attempts at developing computing education ontologies have been helpful, but are also incomplete and have had difficulty mapping across different levels of education. Sabin et al. [86] and the IT2017 report [96] have shifted the curriculum discourse towards using computing competencies as a means of describing computing degree programmes in ways that can be meaningfully compared 
across nationalities, languages, geographical locations, and, possibly, across computing disciplines. The IT2017 report presents a scholarly-based definition of IT competency as a triad of interrelated dimensions of knowledge, skills, and dispositions situated in a professional context [67, 74, 79, 89].

Our goal is not to create a computing education ontology, but rather to present a competency model and method that can be used to describe the various computing disciplines in general, and computing degree programs in particular. Utilising a richer competency approach affords minting of a new currency, a newer means of describing and comparing computing degree programs and their components worldwide.

\subsection{Project Background}

This working group report contributes methodologically to the Computing Curricula 2020 (CC2020) project, and includes reviewing and formulating sets of disciplinary-relevant competencies used in computing education. The goal of the current paper is to develop a comprehensive, scholarly-based competency framework, as well as guidelines for modelling competencies in computing education suitable for comparing degree programs across nationalities and disciplines by enabling comparisons of the competencies intended in each degree program.

The goals of the CC2020 project include developing a better conceptual framework for explaining computing education and its link to quality and innovation. Hence, this paper develops the CoLeaF model as a method for helping to describe relationships between competencies, bodies of knowledge, professional profiles, educational contexts, and degree programs.

The competency model focuses on the meaning and use of competencies in an educational framework. Using this approach we describe patterns for how to frame a competency and illustrate its structure. For example, the IT2017 report [96] describes the educational foundations and meaning of IT competencies. Since descriptions of computing disciplinary domains in CC2020 draw upon existing ACM/IEEE-CS and other curricular frameworks, it is important to standardise terminology and suggest ways to harmonise terminology over time.

The CC2020 effort also envisions developing an open access, online comparison tool. The tool is expected to leverage this and other scholarly work so that stakeholders (e.g., computing educators, administrators, etc.) could use it to develop curricula and course descriptions. For example, they could use the comparison tool to inspire or to motivate change in an existing curriculum, to correct or to assess a given curriculum, to compare one curriculum to another, or to contrast one computing discipline to another [86].

\subsection{Team}

This study was carried out by a team of ten co-authors as part of a Working Group session at the 23rd Annual Conference on Innovation and Technology in Computer Science Education (ITiCSE '18). While the work began prior to the conference, the co-authors worked intensely from 30 June through 3 July, 2018 creating the outline and initial findings for this project, and planning the followon work. Figure 1 shows the team at the conference.

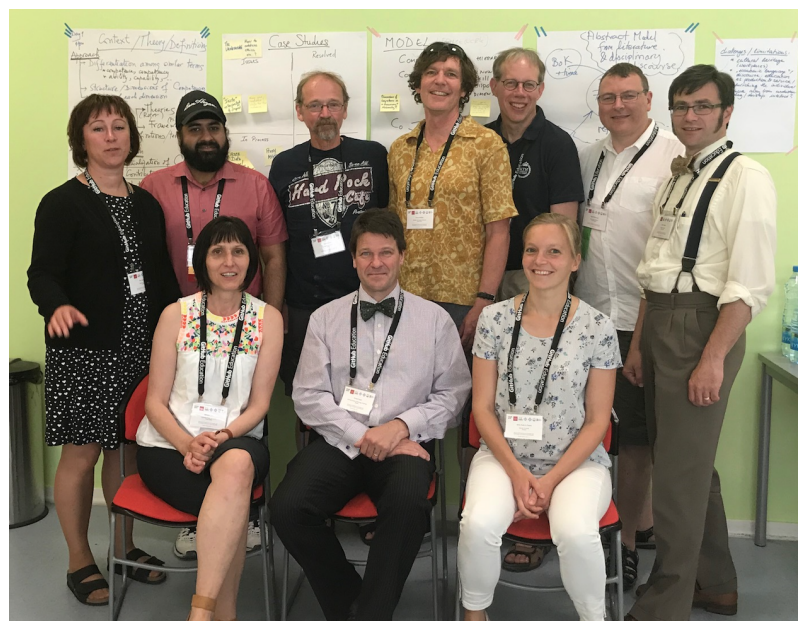

Figure 1: Working Group Team at ITiCSE'18. Standing (L$R)$ : Åsa Cajender, Amanpreet Kapoor, Mats Daniels, Charles Wallace, Viggo Kann, Roger McDermott, Steve Frezza; Sitting (L-R): Mihaela Sabin, Arnold Pears, Anne-Kathrin Peters (Photo: Sixten Cajander Daniels)

As a whole, the ten-member team represented four U.S. institutions, two Swedish institutions, and one Scottish institution, with three of the members having direct experience of the creation of international curricula. Of the ten members, three are sitting department chairs in various areas of computing and collectively they brought a broad range of experience to the project.

\subsection{Contribution}

One of the merits of this study is to propose a more comprehensive and practical set of scholarly-based definitions for the term competency. This work specifically presents an individual competency not simply a sum of knowledge, skills, and dispositions. Instead, it proposes that a well-formulated competency statement requires the presence of all components (potentially many from each component category) and a process that integrates those in a meaningful way in a given context.

This assertion, while rooted in the extant literature, asserts this recognising that the term 'competency' has varied and often conflicting definitions (See [12, 42, 48, 50, 63, 71, 85, 105] and others). We make three principal observations in this regard. First, a competency is about developed proficiency in a particular area of work. Second, a competency has a structure and integrates knowledge, skills, and dispositions. Third, competencies in a learning environment do not stand alone, but exhibit dependency relationships to describe different learning progressions in a degree program or a curricular unit where learning occurs.

The notion that a competency is fundamentally about demonstrated performance in a work-related context is reasonably asserted in the literature. A competency is understood in specific settings and by carrying out goal-oriented, concrete tasks. While some work-related expectations can be aspirational, they ultimately are performative and can be evaluated, as discussed in the body 
of literature surrounding outcomes assessment [46]. This study extends this body of literature in Section 2 .

The second key understanding of competency concerns the internal structure of a competency. This is a response to the cognitivefocused patterns common to many (most?) computing degree programs [16,55] and to the knowledge, skill, ability and similar formulations $[30,54,105]$. In this sense, we argue that the integrated knowledge, skills and dispositions model proposed is better aligned with a more holistic approach to education and assessment, in the sense that modern behavioural science research is "very clear that each person responds as a 'total organism' or 'whole being'" [56].

In this sense, this report represents an extension of the existing literature in competency modelling, as it proposes that a competency is not the sum of its parts, but rather the contextually-related synthesis of these parts extending the 'bundling' approach. The understanding of disposition, and extending how and why this is essential to the effective application of competency-based education (e.g., [89]) is one of the core intellectual contributions of this work.

\subsection{Approach}

With the central goal to develop a means to describe contextualised competencies, the approach taken in this study was primarily twofold: 1) to examine the theory of competency, and 2) to conduct a series of case studies to demonstrate the potential applications of the research. Here, the theoretical work was to inform and underpin a model, while the various retrospectives were intended to help understand issues with the various approaches, and help inform how to develop such models for use in education.

A major contribution to the model development was a thorough examination of the educational scholarship surrounding competency, competency modelling, and how it has been used in different educational settings. This is set forth in Section 2, which includes a definition of our proposed competency model. Section 3 then describes how this competency model can be used as a competency learning framework. These contributors to the model development are captured in the box in the upper right hand corner of Figure 2.

Other significant avenues to explore our understanding of the competency concept were sets of data-driven case-studies from faculty and students' perspectives. These were conducted in Sweden, and are detailed in Section 4. The purpose of conducting several case studies was primarily to understand key educational stakeholders' perspectives, and secondarily to inform both the developing model and methods for developing competency descriptions in practice. These are captured by the two lower boxes in Figure 2.

We argue that much of the previous work in developing computing curricular guidelines has utilized a knowledge-unit-plus-time approach with the goal of creating Body-of-Knowledge (BoK) collections that are contained in various ACM/IEEE-approved computing disciplinary documents (e.g., IS2010, CS2013, SE2014, or CE2016) and are essential sources of information for our work. The goal of these avenues of research was to develop a theoretical framework for competency learning that can be applied to create descriptions of competencies situated in different contexts.

We illustrate an example of use of our work in Figure 2. The context is a degree program at a hypothetical university that was originally defined based on the traditional knowledge-unit-plustime approach. The black arrow indicates one route from these BoK collections and their time measures associated with knowledge units through the proposed theoretical framework to arrive at a description of a contextualised set of competencies defining the education degree program in terms of competencies within our Competency Learning Framework (CoLeaF).



Figure 2: Combined Theoretical \& Retrospective Approach

\section{THEORETICAL BACKGROUND}

The educational literature on competencies and their role in structuring the learning process is vast, encompassing as it does ideas about epistemology, agency, skill-acquisition, and the comparative claims of different competency frameworks. This has led to a variety of terminology, some of it contradictory and almost all of it confusing when trying to determine the scope of the basic definitions of the theory. Indeed, some researchers have stated that it is no longer possible to reconcile effectively the various uses of the terms in question and that the use of competency should be abandoned completely [107]:

Winterton et al. state it this way: "There is such confusion and debate concerning the concept of "competence" that it is impossible to identify or impute a coherent theory or to arrive at a definition capable of accommodating and reconciling all the different ways that the term is used." [108]

Van der Klink and Boon [103] make the case for the popularity of the concept due, ironically, to the lack of clarity over the term competency and maintain that the number of definitions "is probably incalculable" [104]. A literature study by Stoof, Martens, and Van Merriënboer [95] places the word in the "wicked words" category, meaning that its limits are hard to determine, which makes complete agreement on its meaning illusive. Despite its continuing fuzziness, the term promises to be useful in bridging the gap between educational outcomes and job requirements [52, 103].

Some of this confusion arises from the failure to disambiguate the fundamental terms associated with competency, which, in everyday language, are often used synonymously, specifically the words competence, competency, capability, capacity, ability. Moreover, it has sometimes been the case that the plurals of competence and competency are not defined to be the simple plural extension of the singular term. In addition, words which have come to denote 
components of competency, such as knowledge, cognitive abilities, and skills have also been defined in ambiguous ways, which again leads to confusion. For example, do we talk about the skill of playing the piano or a competence in piano playing or capacity to use piano playing in a concert?

Competencies as a conceptual framework for valuing the outcomes of higher education can be traced back to the 1970s and legal nursing and teacher vocational training programmes in the U.S.. These programmes emphasised the acquisition of the behaviour exhibited by outstanding professionals to study and develop desired skill sets [44]. The resulting approach to studying skills to copy behaviour did not produce intended competencies and consequently the experiments did not attract much of a following. Although there has been renewed interest from labour organisations and vocational education in the concept, it was only at the end of the 1990s that higher education began to show interest and renew its participation in the conversation. Klink, Boon, and Schlusmans [104] highlight the following contributing factors: 1 ) a shift in the job market towards increased career and professional mobility; 2) the emergence of the "knowledge worker" and "knowledge economy" in which application of knowledge and skills and "the motivation to keep learning" are essential to one's personal and professional growth; 3) new trends in higher education in response to an increasingly dynamic and complex world that makes sole acquisition of technical knowledge insufficient; and 4) innovations in learning sciences and education, such as participatory learning, deep learning, and contextualisation, have evoked a switch "from knowing to learning".

In conclusion, the persistently challenging problem of transferring learning to new situations coupled with the move from knowledge to learning has created favourable conditions for the popularity of the terms competence and competency despite ongoing debate on their meaning and use in curriculum development. In the reminder of this section, we give some indication of the range of meaning which these terms have inherited and the historical context in which they have been used. Our examination of the relevant literature also informs the working definition of competency we present in this paper. Based on this definition we propose two models, a competency model (CoLeaF) and a competency learning model, to assist the development of curricular guidelines and implementation of degree programmes.

\subsection{Basic Definitions and Theory}

\section{Definitions.}

Competence/Competency. In general, we understand "Competence" to mean the state of being able, or the generic capability which is a necessary requirement to perform, or the set of characteristics which enable performance.

- Some authors distinguish between the concept of competence and competency with competence generally referring to functional areas and competency to behavioural areas.

- When related to vocational and professional education, the concept can also be defined in other words: Professional competence is seen as the generic, integrated and internalised capability to deliver sustainable effective (worthy) performance (including problem solving, realising innovation, and creating transformation) in a certain professional domain, job, role, organisational context, and task situation (following Mulder [62]).

Armstrong [4] sought to differentiate between competence and competency:

- competence describes what people need to be able to do to perform a job well; the emphasis is on doing perhaps in terms of achieving the desired output?.

- competency is defined in terms referring to those dimensions of behaviour lying behind competent performance. These are often referred to as behavioural competencies, because they are intended to describe how people behave when they carry out their jobs.

Competent. Competent is the adjective describing being adequate or qualified and having the abilities or qualities to function and develop.

Competence can be used in different contexts:

- Competence as a prerequisite, such as the specific education and training requirements necessary for permission to practice within a particular occupation;

- Competence as an outcome, that is, performance to a set standard;

- Competence as a capability exercised in accomplishing specific work tasks, i.e. competence as a practical accomplishment [43].

Woodruff [109] suggested that the term competency was used to refer to two factors:

- the proven ability to perform a job competently, i.e. to the standards required in employment;

- the sets of behaviour the person must display in order to perform the tasks and functions of job with competence.

Passow defines competency as "the knowledge, skills,abilities, attitudes, and other characteristics that enable a person to perform skillfully (i.e., to make sound decisions and take effective action) in complex and uncertain situations such as professional work, civic engagement, and personal life" [71]. This formulation is picked up and defended by Pikkarainen:

The traditional dimensions of competence: knowledge, skills and attitudes or head, hand and heart can now be seen and restructured ... to better understand the wholeness of the competence. Attitudes, skills and knowledge are not separate competences or competence areas, but rather components in one and the same whole competence. We could say that skills without knowledge are blind, knowledge without skills is empty, and both knowledge and skills without attitudes are inert and ineffective. This view stresses that knowledge and knowing as cognitive action is really action which requires skills and attitudes just like with any material action. The latter respectively requires and formats knowledge and skills, and will not take place at all without a right attitude, i.e. wanting and having to do [79][p. 632].

Implications of these definitions.

We note that there is no consistent differentiation between the terms "competence" and "competency" and that some languages 
have a single word for this construct. We have decided to choose the English word "competency" to model that "common currency" which will help stakeholders of computing education describe, compare, and communicate about computing degree programs.

\subsection{Dimensions of Competency}

How do we characterise or categorise a competency? If we only list the elements that make up its internal structure, we arrive at a list of knowledge elements or description of requisite skills which makes comparison with other competencies difficult. We could look at common elements on the lists but this does not give us a real indication of how a competency is being used. Another approach is to try to characterise the competencies by their properties when applied in the world.

Mulder identified ten competency dimensions [63]. Each dimension is a more or less independent lens for external observation of the use of a competency in the world. These dimensions are:

(1) Centrality: the degree to which a competency is central to a professional engaged in some field. The range would be from central to peripheral. Central competencies are essential for effective performance and being used frequently, whereas peripheral competencies are less important. So, for example, if we consider the competencies of a software engineer, a programming competency might be considered central whereas a financial management competency might be considered more peripheral.

(2) Specificity: (which Mulder labels Contextuality) the degree to which a particular competency is generic or specific to a particular situation or context. Here, being more specific means being more-or-less related to a specific situation which may be an individual circumstance or a particular content domain. More generic competencies are applicable across wider contexts. For example, social competencies tend to be more generic whereas those derived from educational contexts tend to be more specific. There is a high consensus though that competencies actually get meaning in a specific situation [62].

(3) Definability: the degree to which a specific competency can be clearly defined.

(4) Developability: the degree to which a competency can be developed, in the sense of growth mindset [110], or is seen as a fixed personal qualities.

(5) Dynamic nature: the degree to which a competency is triggered by or expressed in certain circumstances. Some competencies appear to be part of the background human condition, whereas others come into action in specific circumstances.

(6) Knowledge inclusion: the degree to which knowledge is considered to be important. Some competencies, especially those drawn from a practical or vocational context, appear to have a more implicit knowledge component, being mostly dependent on the developed skill of the practitioner; in other competencies, the knowledge component is more explicit. An example of the former would be the competency to make a wooden cabinet carpentry joint which relies on the skill of the carpenter. An example of the latter might be a competency to solve a differential equation.
(7) Measurability: the degree to which competencies can be measured. Some competencies appear to be directly measurable, such as the competency of singing a particular note. Others appear harder to measure because they involve assessing various proxies which may require significant interpretation or analysis.

(8) Mastery: the level to which a competency is achieved. Some competencies, such as driving a car, can be more-or-less fully achieved after a period of study. Others, such as the competency for drawing a portrait, appear to be more openended.

(9) Performativity: the degree to which a competency relates to performance. This may be linked to measurability if the competency is based on an explicit demonstration but there are some competencies which are less easy to measure but are nevertheless essentially performative, e.g. intercultural competency.

(10) Transferability: the degree to which competencies can be successfully applied in a range of professional situations.

These dimensions play a role in our understanding of a competency. For example, if one considers "driving a car" as a competency, then one could consider that its centrality would be limited to a small set of professions; its specificity would be somewhat contextual to right- or left- side of the road driving; Its definability and developability would be generally good for healthy adults; Its dynamic nature would be low, as much of the mastery of 'driving a car' involves the development of implicit knowledge and skill applicable in a wide variety of times, conditions and locations, and not triggered by very specific conditions; Its knowledge inclusion would be mixed, as there is both implicit and explicit knowledge needed; Its measureability would be reasonably good, as examples of levels of driving skill have been established in various settings; Mastery, as mentioned, based on its measureability is also very high; Its performativity would be high, as this is not demonstrable outside of a 'car' as would its transferability.

What these dimensions provide is a language in which to consider how statements of competency can be examined and compared. Competency models aim to help structure developing competency statements for descriptive or prescriptive use.

\subsection{Existing Competency Models and Frameworks}

Existing competency frameworks provide insights into different types of competencies, as well as different ways of modelling competencies, as we describe in the following.

Societies and organisations (professional, national, or international) have embarked on initiatives aimed at improving educational systems worldwide to successfully prepare students in a rapidly changing, interconnected, and complex world. These efforts have the common, prevalent trait of proposing frameworks built upon the notion of competency. The Organisation for Economic Co-operation and Development (OECD) through its International Student Assessment (PISA) prioritised education for global citizenship and global competency and proposed an assessment framework for which they introduced the notion of global competency as a multidimensional capacity [33]. In their definition, globally 
competent individuals have "the capacity to examine local, global and intercultural issues, understand and appreciate different perspectives and worldviews, interact successfully and respectfully with others, and take responsible action toward sustainability and collective well-being". Structurally, global competency in the PISA OECD framework is composed of knowledge, cognitive skills, and social skills and attitudes.

Shifting attention to the outcomes of the educational process has increased interest in defining competencies in terms of what makes students successful in their future endeavours, whether success relates to personal development, employment, or participation in society [97]. As more organisations and consortia have proposed frameworks of competencies, the more ambiguity and uncertainty have surrounded the definition of competency and qualifiers accompanying the term competency, such as "key", "core", or "twenty-first century", that have emerged from the construction of different frameworks. The UNESCO report [97] gives the example of the European Union Reference framework [99], which defines competency as "a combination of knowledge, skills, and attitudes appropriate to the context" and set apart key competencies which all individuals need, on a full spectrum from personal development to "active citizenship, social inclusion and employment". The report also recognises the recurrence of similar competencies in different reference frameworks, although the degree of importance of each competency and proposed classifications exhibit variations. For example, some frameworks propose the four 'Cs' - communication, creativity, collaboration, and critical thinking as key competencies.

UNESCO International Bureau of Education [2] examined curricular frameworks in countries from all regions in the world and found that almost 90 countries mention generic or cross-cutting competencies in their general education curricula. Among the most prevalent generic competencies were social competencies, such as empathy, respect for others, and communication. Other competencies include problem-solving, creativity, digital competency, and numeracy. Generic competencies mentioned by almost half of the countries were civic competency, collaboration, critical thinking, and entrepreneurship.

In Germany, a three-dimensional competency model is used in K-12 computing education [41] (see Figure 3 and its English translation in Figure 4).

In the K-12 Informatik model it is argued that learners develop competency by engaging with content ("Inhalte"), in different processes ("Prozesse"). What is termed as content (e.g. algorithms, systems) corresponds to knowledge. What is described as processes relates to skills that are acquired in practices (e.g. model and implement, present and interpret). Content and skills are seen as interwoven, the content can be identified from analysing a skill and vice-versa. For example, content (knowledge) can be enacted in presentations and interpretations, and content (knowledge) can be deduced from studying processes. The third dimension "Anforderungsbereiche" describes a quality of engaging with content and skill, how much the learner makes the content and skills his or her own, which relates to dispositions. In the present work, we suggest to understand competency as more than its components. We discussed this model and illustration and came to understand that a competency must be more than the components of a competency.

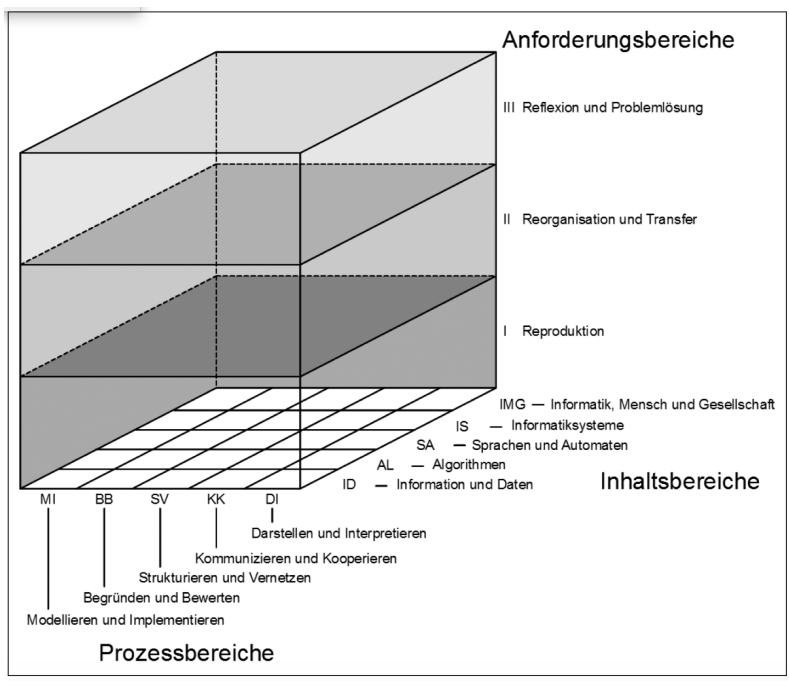

Figure 3: Model used for K-12 "Informatik" education in Germany [42]

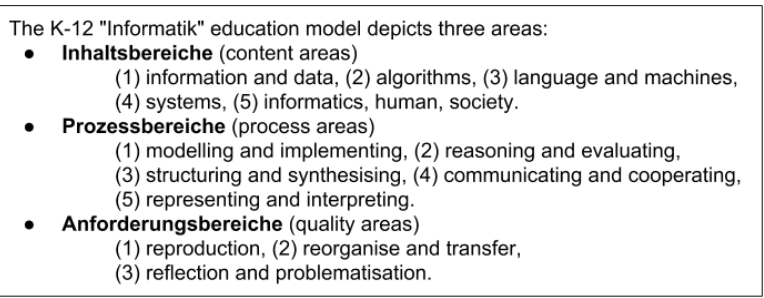

Figure 4: English translation for Figure 3

Bachelor's and master's programs in Informatics [42] recommend content and competency areas. Examples for competency areas are technological competencies (where examples of content component of these competencies are computer organisation, databases, security), cross-disciplinary competencies (whose content domain pertain to societal, ethical, economical, environmental aspects of computing), and method- and transfer-based competency (e.g. strategies for knowledge acquisition).

Other frameworks classify competencies into cognitive, intrapersonal, and interpersonal. Education for Life and Work report [73] contrasts the generality of 21st century skills manifested at home, school, in the workplace, and in social networks with their view of 21st century skills as "dimensions of expertise that are specific to and intertwined with - knowledge within a particular domain of content performance". The close link between knowledge and skills, the committee of the report argues, factored into choosing the term of "competencies" for the 21st century skills. The report organises the competency domains into cognitive, involving "reasoning and memory", interpersonal or "capacity to manage one's behaviour and emotions to achieve one's goals, including learning goals", and interpersonal domain, related to "expressing ideas, and interpreting and responding to messages from others". 
The classification of the 21st century competencies proposed by the Education for Life and Work report [73] aligns competencies with the skill categories in the Occupational Information Network $\left(\mathrm{O}^{*} \mathrm{NET}\right)$, the U.S. primary source of occupational information that frames occupational skills covering over 1,000 occupations in the entire U.S. economy [21]. The O*NET cross-functional skill categories that are mapped to the 21st century competencies include social skills, complex problem-solving skills, system skills, process skills, and content skills. It is important to point out that none of the 21st century intrapersonal competency categories (intellectual openness, work ethic and conscientiousness, and positive core self-evaluation) has a corresponding $\mathrm{O}^{*} \mathrm{NET}$ skill set. This gap re-enforces our argument for considering dispositions as a necessary competency component that better aligns individual education outcomes with individual outcomes in the world of work, civic engagement, and social participation.

\subsection{Working Definitions of Our Competency Model}

We view competencies as personal qualities causally related to demonstrated proficiency or accomplishments in an area of work, civic engagement, and social participation. Competencies tell how good one is in a particular line of work, whether on a job, in a profession, or other socially constructed opportunities, such as an interest group, a community-based organisation, or a type of civic engagement.

Competency integrates knowledge, skills, and dispositions and is context -situated. These integral components of competency manifest in observable and tangible form within a work context:

- Knowledge or "know-that" are predominantly cognitive or intellectual qualities that refer to mastery of core concepts and content knowledge

- Skills or "know-how" are more practical qualities that people develop and learn over time with practice and through interactions with others

- Dispositions or "know-why" and "know-yourself" are affective or dispositional qualities, encompassing attitudinal, behavioural, and socio-emotional qualities of how disposed people are to apply knowledge and skills to solve problems or address issues of personal, social, or workplace-related interest

- Context represents relevant and authentic situations related to problems/issues and aspects of work in which competencies manifest.

The knowledge component of competency is understood as knowledge development and relates to conceptual learning theorised by Piaget as cognitive schemes through which an individual makes sense of the world and includes sensory information in his/her existing cognitive structures (assimilation), which are modified as a result of the individual interactions with objects in the world (adaptation) [78, 90]. Although Piaget emphasised the significance of the child's social environment for knowledge development, in his writings knowledge is portrayed as schemata in the individual's head with little attention given to social aspects. The most significant influence on the learner's conceptual learning, argued by the developmental psychologist David Ausubel [5, 90], is their existing conceptual learning in the target domain and that prior knowledge influences learning. In the 1990s, conceptual understanding purely in terms of cognitive processes in the individual shifted $[45,90]$ to take into account the social context in which individual functions, in light of Vygotski's work decades before on the role of individuals' interactions with the social environment on their development.

Building on the definition of skill as know-how or the capability to do something [34], we observe that skill refers to carrying out goal-oriented tasks by engaging in practices that are disciplinerelated. Science standards in K-12 education in the U.S. complement content areas or core ideas with practices (instead of skills) to "emphasize that engaging in scientific investigation requires not only skill but also knowledge that is specific to each practice". Practices are also included in K-12 mathematics and computer science standards $[35,80,94]$ to link learning the discipline with aspects of work in a profession (what engineers or computer scientists do in the workplace). Know-how develops through experience in everyday practice (science and engineering labs, business case studies, and other discipline-specific learning and professional environments), through learning-by-doing and learning-by-interacting with colleagues [34].

A famous and useful framework for skill development, created by Stuart and Hubert Dreyfus [27], helps with the understanding of skill as a person's progress, practice, and acquired experience that takes time, as the person moves from rule-based behaviours as a beginner to fully embodied, intuitive, and game-changing behaviours as a master [25].

Our working definition of disposition draws on Weinert's definition ([106], pp. 27-28), which identifies "cognitive abilities" and skills, along with a third construct described as "motivational, volitional, and social readiness and capacity to use" knowledge and skills that contribute to "solving particular problems" and applying their solutions "successfully and responsibly in variable situations." Research in education, psychology, human resources, and professional training has examined extensively this third construct that pertains to Bloom's affective domain of learning outcomes. Many models and frameworks were proposed to advance the theoretical and applied knowledge of human qualities that play a role in personal, intellectual, and professional development of an individual. A recurring, single term in the literature that capture those qualities is disposition. The definition of competency offered by Hubwieser and Sentance [48] identifies "a quite complex disposal of behaviour that can be applied" to carry out goal-oriented tasks or solve problems with real-life relevancy. Their definition, like Weinert's, places the dispositional manifestations in a work-related context.

Overwhelming evidence from a diversity of fields, including psychology, philosophy, cultural theory, neuroscience, feminist studies, and science education, indicate that "affect and cognition cannot be meaningfully understood as disparate entities." [1]. A contemporary view on the importance of the affective domain on learning is that "affective dimension is not just a simple catalyst, but a necessary condition for learning to occur" [76]. In attitudinal research, the definitions of attitude and its related terms value, belief, feeling, and emotion have not reached a universal agreement and one "is unlikely to occur in the near future and may even be undesirable" [53]. 
In recent years various educational efforts have increasingly embraced the term competency. Some notable examples include public education goal statements and skills frameworks proposed by various nations and European Union, the Programme for International Student Assessment (PISA) [33], college and career readiness framework by the U.S. Council of Chief State School Officers [67], competency-based education [58], and industry-specific skills frameworks (including computing-related frameworks such as SFIA and EITBOK). Competency-based education has reached all levels of education, from kindergarten to secondary $[58,93]$ and to professional graduate education [83]. These and similar efforts consistently include the terms knowledge and skills in their descriptions of competencies, and, invariably, add to those descriptions something else, using terms such as behaviours, habits, beliefs, attitudes, values, dispositions, emotions, feelings, personal traits. Two terms in this list (which is not exhaustive by any means) have gained predominance, attitudes and dispositions, with the latter receiving more traction recently. We favour the choice of a single term, namely, dispositions, to accompany the well-known terms of knowledge and skills in our working definition of competency. To reach more definitional cohesiveness, facilitate conversations, and engage multiple stakeholders in concerted efforts around competencies we find helpful to include three contributing terms: knowledge, skills, and dispositions (See [79] among others).

Our preference for the term dispositions draws on studies from teacher education programs, learning sciences, and educational psychology, which examine the affective domain of student learning and teaching practices. We have also been inspired by research on student engagement as quality of effort, interest, and willingness to participate in learning [57] and the indexing of the student engagement levels by three types of criteria: cognitive, affective, and behavioural [22]. These criteria assess student learning through the lens of mental effort (cognitive criteria), investment and emotional reactions (affective criteria), and active participation (behavioural criteria) in learning tasks.

The idea of dispositions is that "people's behaviour is guided not only by knowledge and skills but also by predilections or tendencies [...] in intellectual, social, and moral conduct [...] exhibited under certain conditions" [75]. John Dewey preferred the word "habit" and observed that dispositions suggest "readiness to act overtly in a specific fashion whenever opportunity is presented" [26]. Other names under which dispositions appear in the literature, as noted in [19], include habits of mind [24], mindsets [28], and learning power [23].

A dispositional view on competency offers the means to distinguish between what a person can do from "what a person does do within the limits of his or her capacity" [7, 79] or, in other words, what "turns abilities into action" [84]. In the field of teacher education research, Schussler [89] observes that the term dispositions is less clearly defined than what teachers should "know and be able to do", idiom indicative of knowledge and skills development in teacher preparation programs. Despite the lack of clear definition, teacher education accreditation standards in the U.S. use the term dispositions alongside knowledge and skills in teacher education [29]. As personal qualities, dispositions come from inside but are manifested on the outside through application of knowledge and skills [89]. Borrowing from Schussler's definition of dispositions expected of effective teachers, we adopt the view on dispositions as "point of inception", from which one's thinking and actions emanate, with a "point of convergence", representing one's filter of taking in external influences of the environment. The convergence-inception duality of the disposition locus is not dissociated from a socio-cultural frame in which dispositions live [19]. What drives the inclusion of dispositions in teacher education curricula in the U.S. is the "programmatic necessity to prepare teachers who will be committed to all learners' learning and growth" and moral and ethical responsibility to teach all students "fairly and equitably". The challenge that dispositions' inclusion in teacher education standards poses extends to a similar challenge from including dispositional qualities in our working definition of competency: empirical measurement [14] and how to frame and assess student dispositions.

To help computing education community move forward in its consideration of computing competencies, we propose to follow teacher education community call-to-action more than a decade ago when they were seeking a common ground for discussion around dispositions in teacher education curricula, that is, opening a dialog though efforts such as the CC2020 project, development around updates to computing curricular reports, and further researching the nature and role of competencies in computing education. We offer our working definition of competency to initiate such dialog.

Conceptualising competency in terms of situated knowledge, skills, and dispositions in an authentic context creates the opportunity to describe a discipline or a disciplinary degree program in more direct connection with the students and their agency to learn in the discipline and graduate successfully from a degree program. With the learner at the centre of the educational enterprise, traditional bodies of knowledge "come to life" and push educators to think harder and be more intentional about not only what content their degree programs should comprise, but also what should happen in their classrooms: what type of learning activities would engage individuals with the content knowledge, through what practices, for what purpose, and why students should care about learning the content. In addition to learners and educators, competencies do a better job translating what the outcomes of education are to other stakeholders, such as employers, policy makers, professional societies, other communities, and general public. These stakeholders are direct beneficiaries of competency research, whose "main purpose is to define intended learning outcomes of educational processes, as required by the 'customers' of these processes" [48, $\mathrm{p}$. 229-230].

\subsection{Challenges, Potentials, and Implications for the Application of Competency Models}

The concept of competency and its application is however not without potentially negative implications, as critically discussed in $[10,79]$. We review some of the different arguments for and against using competency models and argue that the concept of competency does bring forward the current discourse in computer science and engineering education that focuses on technical content and skill, however that the critical discussions must continue to inform the use and development of competency models.

Narrowly economic, utilitarian, individualistic, and ideological commitments of the discourse of competency have been criticised 
by many [79]. Barnett [6] e.g. argues that competency models are used to ensure the needs of the labour market, to produce the required knowledge. University education becomes increasingly steered by economic interests, which undermines broader educational goals such as giving the learner opportunities to develop self. The influence of economics is visible in the language used to define and discuss the concept of competency. For example, competencies are described as learning outcomes from the viewpoint of the "customers of education" [48]. In this work, we use the term stakeholders and argue for the importance to consider the multitude of stakeholders of computing education, i.e., students, educators, labour market, and society at large.

In the development and application of competency models, the role and purpose of university education needs to be taken into consideration. Traditionally, universities were autonomous institutions in teaching and creating knowledge [6]. The more education is operationalised by other stakeholders, the less autonomy universities are granted and the more they becomes a service provider to others.

Competencies are defined as qualities that make action or performance possible and as such understanding tends to get a less significant role in the discourse on competency-based education $[6,81]$. The term "proficiency" has been proposed to de-emphasise performance and to draw attention to individual qualities [93]. Going back to the origin of the notion of competency, the term competency is connected to high-order learning, associated with terms such as "Bildung", where the individual and holistic development is considered central [79].

Competencies describe what the individual is or should be able to do, behaviour however is always shaped and constrained by the environment [18]. We can only observe 'manifested competency', i.e. competency as it becomes manifest in a situation and in an environment [79]. If students do not demonstrate competency, the issue is either the student's competency or the learning environment. Competency on the one hand side gives agency, considering that competencies allow action, but what or who is seen as competent is negotiated in social contexts, which limits agency.

Considering the learning environment and different stakeholders in the specification and application of competency models is especially important because of current structural inequalities in our educational system [49, 81]. For example, computing has been constructed in ways that are associated with masculinity, masculinity as it is re-produced in the western world, which marginalises women $[31,88]$. A dominant competency model that is not established taking into account the experiences and interests of different interest groups or demographics risks to perpetuate current inequalities.

Competency should therefore be seen as a concept which contains and somehow balances different sides of an individual person's qualities such as skills, dispositions, and cognitive functions. Additionally, it should connect and balance the views to an individual person on the one hand, and to the social and other environments of that person on the other hand. Thirdly, it should be connected to the deep essential or ontological features of a human being and it should help in planning, managing and measuring educational activities. Further, it should perhaps be applicable to the theoretical structures of scientific educational research and at the same time be usable in discussions between practitioners of education and university managers [79].

Competency is a useful tool to think about the learner in more holistic ways than in terms of cognitive capabilities. It helps to improve the employability of degree program graduates at the same time as it can help to acknowledge the learners in their individual process of developing hand, head and heart [79]. With this work, we are clarifying dispositions, a dimension that has until today mostly been put aside, e.g. "in lack of psychological expertise" [55, p. 5], in order to develop a more holistic education. We argue that this can help to increase the comparability of educational programmes, and to assess learning in more holistic ways. In developing and applying competency models using our competency learning framework, we should keep in mind that there may be less utilitarian values, such as carefulness, thoughtfulness, humility etc. [6] that we are not currently including in our models (e.g. in lack of assessment methods or language to express them formally). We should also keep in mind the following questions when implementing competency models: Are we constraining students? What learning behaviour do the competencies cause? How does the a competency-based educational system "form the students"? What are the ideal students?, Who are the students whose voices currently are not heard?

\section{COMPETENCY LEARNING FRAMEWORK}

To provide a structured approach to deriving and describing competencies we define a competency-based framework for learning (CoLeaF). We begin by providing a stricter definition of the internal structure of a competency in order to establish the basis of a more usable and formalised competency model. We then describe how competencies can be though of using the notion of hierarchies of competencies.

\subsection{Structure of a Competency}

In order to be able to represent competencies more strictly we define a competency is an integrative function consisting of a set of knowledge elements, a set of skill elements, and a set of disposition elements [79], as defined in \$2.4. These three sets are the components of the competency and represent the knowledge, skills, and dispositions associated with performing the competency in a context. Figure 5 depicts a competency $C$ with its knowledge component $C . K$ (with elements $k_{1}, k_{2}, \ldots$ ), skill component $C . S$ (with elements $s_{1}, s_{2}, \ldots$ ), and disposition component $C . D$ (with elements $\left.d_{1}, d_{2}, \ldots\right)$. As discussed in Section 2, competency manifests in a context which is represented by the black box in Figure 5 .

Each competency's components are integral to the competency in the particular context and therefore should not be seen as freestanding entities. Furthermore, a competency is not uniquely defined by its components, and therefore should be seen as more than just the union of its components. As a consequence, different competencies may share knowledge, skill, or disposition components, and may even have identical components, however, the performance aspect may still allow these to be distinguished as independent competencies in different contexts. Finally, it is important to note that this abstract conception of competency achieves manifestation 
(and the holder of the competency achieves agency through performance of the competency) only within a particular context as indicated by the black box of Figure 5 .

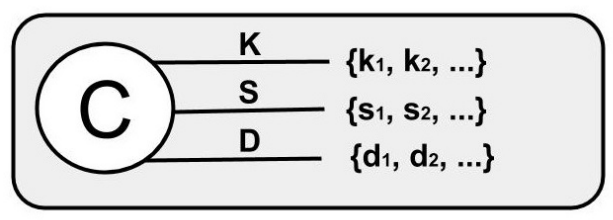

Figure 5: Knowledge, skill, and disposition components of a competency

\subsection{Structure of Competency Learning}

It is important to note that the Competency Learning Framework (CoLeaF) we propose is intended to capture the relation between competencies in a particular learning context and depict a situation at the conclusion of the learning experience described. That is, there is a considerable freedom regarding the temporal ordering of addressing individual learning elements. The framework is intended to capture that learners leverage and build on competencies they have already attained in the process of developing new ones. Hence, competencies in a learning environment do not stand alone but depend on preceding competencies. Dependencies between competencies form a directed acyclic graph. A set of competencies and a dependency relation defined over those competencies thus constitutes a competency learning framework.

Figure 6 depicts a situation where competency $C_{0}$ depends on competencies $C_{1}$ and $C_{2}$. In this case, $C_{0}$ shares knowledge elements $k_{1}$ and $k_{2}$ with $C_{1}$, shares knowledge elements $k_{2}$ and $k_{4}$ with $C_{1}$, and requires an additional knowledge element $k_{5}$ associated with neither $C_{1}$ nor $C_{2}$. There are a few implications of the Competency Learning Framework that is illustrated in this example. For instance, the context of the different competencies in a competency learning framework might be different and learning elements in preceding competencies might become obsolete in more abstract competencies, e.g. $k_{3}$ in the example. A learning element can be obtained separately, e.g. $k_{2}$, but has to be used in the context of the competencies $C_{0}, C_{1}$ and $C_{2}$ together with all other learning elements of the respective competencies in the specified contexts in order to conclude that the three different competencies have been mastered.

In theory we could describe any competency as being without dependencies, but that would soon become unwieldy as a learning and/or education structuring aid. We thus assume that a competency learning framework always is constructed of a directed acyclic graph for all except the most elementary competencies. In addition to allowing individual learning elements to be addressed at different times in an educational setting, we also want to point out that when instantiated, the Competency Learning Framework (CoLeaF) presented here may have multiple topological orderings, suggesting that there might be different linear learning progressions for the same competency. Figure 7 gives an example of such an instantiated CoLeaF framework. Here the numbering of competencies shows

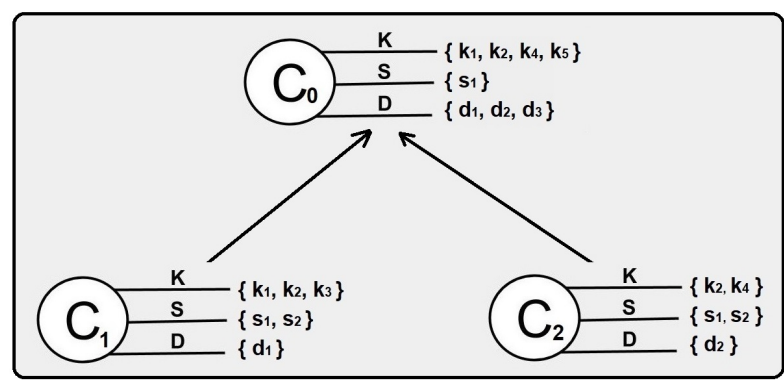

Figure 6: Competency Learning Framework (CoLeaF)

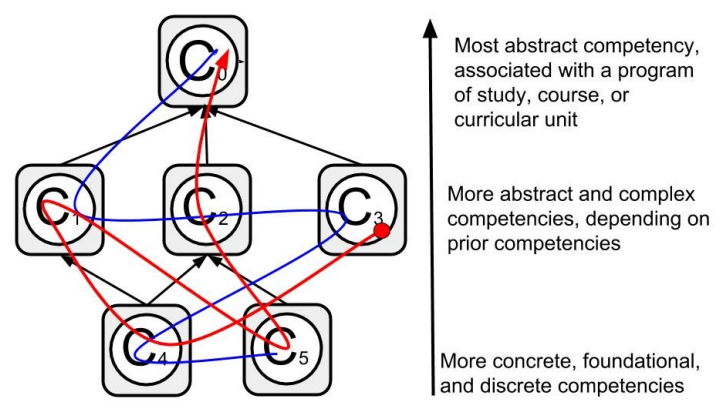

Figure 7: Instance of Competency Learning Framework with learning progression $C_{5}$ to $C_{0}$ from more concrete and fundamental competencies to more abstract and complex competencies

one valid reverse topological ordering, meaning that to achieve $C_{0}$, one would achieve, $C_{5}, C_{4}, C_{3}, C_{2}$ (based on having achieved $C_{4}$ and $C_{5}$ ) and $C_{1}$ (based on prior $C_{4}$ ). It should be stressed, however, that learners may work concurrently on multiple competencies, so a linear progression from one competency to another may not reflect a true temporal learning order.

\subsection{Types of Competencies}

The CoLeaF framework (as previously discussed) defines each competency as an integration of a set of three learning components: knowledge, skills, and dispositions. In a specific setting a given competency may emphasise one component over the others. For instance, some competencies are knowledge focused like competence in Theoretical Computer Science where the knowledge learning component is more highly emphasised than the skill and disposition dimensions. On the other hand, other competencies like "perseverance in the face of technical challenges" can have a higher level of the disposition dimension in comparison to knowledge and skill. In addition, competencies can also be categorised as generic or specific, depending on references to the problem context. Take for instance the competency of "relevant and responsible problem solving". Problem solving can be a generic competency (as in the current debate over computational thinking) as well as a specific competency (situated as the ability to apply CS techniques to a given task description), depending on the context of the problem definition at hand. For instance, the competency might be considered generic if 
we consider problem solving as an holistic competency for a software engineering graduate, while it might also be highly specific if the competency is defined in terms of a narrow assessment or context such as a competency in solving a programming problem where a student needs to demonstrate problem solving when they are provided with concrete specifications for a particular problem and application domain. However, even in these instances the disposition component cannot be excluded, context of problem solving, ethical and cultural dimensions are always present, even though they may be hard to capture.

\subsection{Application of the Competency Learning Framework (CoLeaF)}

The discussion above leads to an important question for this report. How do we apply this framework to formulate or express competencies that capture the performances (expressions of competency) expected from graduates of a program of study, a course, or a curricular module?

In order to define the highest level or most abstract competency of a program, course, or curricular unit, is is necessary to articulate the knowledge, skill, and disposition components associated with an authentic context. This context is crucial, since it provides the motivation for the student, making it meaningful to learn and perform that competency. CoLeaF thus integrates mastering the competency's core content in tandem with practising and developing relevant skills and forming dispositions that positively influence learner agency with respect to sense of self and responsibility for interactions with others.

Competency learning is thus a progression, and using our topdown approach, we can define the set of competencies on which a higher-level competency depends. Learning a competency that does not depend on other preceding competencies implies a set of learning activities that are self-contained, in the sense that they would more likely involve fundamental knowledge, and more basic skills associated with the specific dispositions needed to apply knowledge and skill in an appropriate context.

In many cases, competencies desirable in tertiary computing education have significant dependency chains, typically reaching into students' pre-college experience. These dependencies in student cognitive skills and knowledge are commonly modelled and assessed as 'outcomes' in tertiary computing education. However, current learning outcomes focus primarily on development and assessment of students cognitive skills as a part of the examination process. Formulation of graduate outcomes has been emphasised in some contexts, but is still uncommon in many contexts.

Learning outcomes help educators to focus on student learning progress, measure changes in learners' knowledge and behaviour, and align educational objectives with instructional practices. Educators formulate learning outcome statements to describe learning milestones students achieve in their program of study. At the highest level of abstraction of a student learning progression, learning outcomes express the lofty goals of education, such as act responsibly and knowledgeably to benefit one's self and society. However, many of these more lofty goals and outcomes are not simply cognitive, but rather imply significant skill and dispositional (and affective) components of student learning [59]. To this end, wellstructured CoLeaF statements can help programs make explicit the dispositional aspects of their program's intent, and better design assessments to target the competencies desired of their students.

In its most basic form, for example, a CoLeaF instance modelling the beginning of a learning progression, CoLeaF modeling would involve very specific elements of the knowledge, skill, and disposition learning components. This could be students learning new content knowledge and acquiring supportive skills in a learning environment set up to conducted in a way to engage students, addressing their dispositions to using the associated knowledge and skills. Because competency is normatively assessed through some form of demonstration, this would be through learning activities intended to apply the knowledge content, practice the new skills and reflect the related disposition(s).

Hubwieser and Sentance [48] note that learning outcome statements usually combine "certain knowledge element and a description of observable behavior" expected of learners at the completion of a segment of instruction. The knowledge and behavior dimensions of a learning outcome originates from Anderson and Krathwohl's [3] revision of Bloom's famous taxonomy of learning outcomes [13]. While Bloom dissociated three domains of learning outcomes (cognitive, affective, and psychomotor), his taxonomy is one-dimensional and takes into account only the cognitive domain. The behaviour dimension in Bloom's Revised Taxonomy [3] substitutes the six nouns with corresponding active verbs (ordered slightly differently), and is complemented by dimensioning knowledge from factual to conceptual and metacognitive. In practice, however, the reigning six active verbs (remember, understand, apply, analyse, evaluate, and create), including the overloaded 'understand', and a plethora of synonyms have been extensively used to write syllabi and program objectives that continue to elevate the knowledge or cognitive dimension as definitional of what students learn and are able to do.

\section{CASE STUDIES}

Competencies provide a powerful way to reason about the value that an education might represent for different stakeholder groups. However, the discussion in the paper up to this point has been largely theoretical in nature, with the result that the application of CoLeaF in practice is not entirely obvious. Pragmatic application of the CoLeaF approach is illustrated using two case studies. The first analyses student expectations of their educational programme, while the second applies a body of knowledge based approach.

Our intention is that applying the Competency Learning Framework (CoLeaF) presented in this paper will allow domain and educational system specific descriptions of competencies to be developed and compared. The earlier parts of the paper have discussed notions of competence, and modelling competence. The result is a working definition of "competence" and a formalisation of the composition of competences through aggregation and synthesis of "knowledge" and "skills" mediated and integrated by and through "dispositions".

To understand the intended application of CoLeaF in pragmatic elicitation we provide two case studies, which serve to illustrate how the framework can be applied. We focus on two major examples, though the expectations of many other stakeholder groups 
(e.g. academics, industry representatives, and policy makers) might equally well be modelled in a similar manner.

This aspect of CoLeaF is best illustrated using case studies. Our first case study is an inductive analysis drawing on data collected from students and academic staff regarding which competencies they think are relevant for a specific educational setting. Our second case study examines deriving competency descriptions in a specific domain, here the software testing area, combining previous curricula definitions and Bodies of Knowledge (BoKs) as underlying data.

\subsection{Case Study: Student Perspectives on Competencies}

The first case study draws on student perspectives on learning outcomes and competence formulating competencies from student statements. Moreover, a comparison could be made between fourth year students' and first year students' perspectives related to competencies.

Student perspectives on competencies in Sweden (the target nationality of students for this case study) can also be placed in relation to the program learning outcomes defined in the "Higher Education Ordinance". This case study results in a set of competencies that the students found most important in their education. Their perspectives and the implications for education are discussed by the end of this section.

This this case study provides a strong student perspective, and it is particularly important to note that no effort was made to force a CoLeaF competency structure onto the students' responses or thinking. The goal was to understand how fourth year students saw and experienced competency development in their educational situation. Their impressions of their tertiary degree program, seen through the lens of competency statements, and related to the stated program outcomes provide a rich source of data for the subsequent formulation of competencies using the CoLeaF guidelines.

4.1.1 Competency Statements from Fourth Year Students. Our first case study draws on a data set consisting of competency statements generated by fourth year students in the 5-year Computer Science and Engineering degree program at the KTH Royal Institute of Technology. The data was collected through a mandatory survey administered as an element of the Program Integrating Course [51] in May 2018 at the end of the academic year. The question chosen for this case study, comprises a small part of the overall survey, and was formulated as follows.

There are many competencies that a computer science education should provide. These competencies can be divided into subject-related professional competencies (e.g. skills that are involved in developing, correcting and testing program systems), general professional competencies (e.g. different types of communication and group work skills) and self-regulatory competencies (e.g. competencies that have to do with reflection, planning and learning).

Which competencies do you think are the most important that you have developed during your studies at KTH? (List as many competencies you like, but at
Table 1: Knowledge-focused competency as expressed by 4th year students

\begin{tabular}{l}
\hline theoretical foundation on which programming is based \\
broad knowledge of computer science \\
advanced algorithms and data structures \\
complexity theory \\
programming paradigms ( 2 statements) \\
software production flow and methodology \\
software architecture ( 3 statements) \\
new design patterns to improve your versatility \\
interaction design \\
web development \\
model verification \\
data representation \\
how an operating system really works \\
how a computer really works ( 2 statements) \\
computer architecture \\
computer security ( 3 statements) \\
artificial intelligence algorithms and approaches \\
machine learning ( 3 statements) \\
standard data science tools \\
standard of data managing, databases etc. \\
necessary mathematical knowledge (3 statements) \\
logic \\
Unity \\
general insight into modern digital technology \\
a good picture of the job market
\end{tabular}

least two competencies of each of the three types, one competency per line.)

A total of 834 th-year students answered the question. They listed 404 "competencies", about five per student, of which 162 can be classified as unique.

A thematic analysis of the answers from the students was conducted with the intention to cluster student responses. Some of the listed competency statements demonstrate a student focus on plain knowledge components as a definition of comptence, see Table 1, while others were disposition-focused, see Table 2. The major part, more than $85 \%$, encompasses competencies containing at least one skill component and potentially other compoments relevant in the CoLeaF framework. These were possible to cluster into 11 clusters that we could interpret and name. As an example, the communication skills competencies are shown in Table 3. The clusters and number of student stated competencies in each cluster can be found in Table 4.

Analysis of the student stated competencies in the subject-related professional skills cluster identified three sub-clusters for which we could formulate the following statements: Develop and maintain programs and systems, Analyze and solve problems algorithmically, Be versatile in programming. In the next step we formulated themes for each of the other skill clusters, ending up with the 12 aggregated student expressed "competencies" in Table 5.

It is interesting to note that most of these statements are not competencies in the sense that we have defined them, nor as discussed in the academic literature on the subject. The conclusion we 
Table 2: Disposition-focused competency statements expressed by 4 th year students

self confidence
standing up for myself
scientific way of thinking
ethical awareness
never giving up on solving a problem
accepting multiple solutions to the same problem
curiosity about new technologies
keeping in touch with current research and
technological development
being active and supportive in teamwork
hearing everybody out, finding a way to work
with people that don't match you personally
being attentive
confidence that I have learned a wide variety of
skills and can approach different kinds of problems
feeling comfortable with math and programming
desire and ability to pursue my own projects
importance of knowing the fundamentals of how
a software (like a game engine) works

Table 3: Communication skill-focused competency statements by 4 th year students

communication (13 statements)
to present ideas/results well both orally and in writing (both
$\quad$ as formal presentations but also in discussions,
$\quad$ brainstorming etc) ( 8 statements)
to present ideas to people with less developing skills
to explain technology
oral communication
to speak in public
to get your point across
to communicate in English ( 2 statements)
to argue and discuss in English
writing skills in English, by reflections and papers (2 statem.)
to discuss technical problems with others
to discuss others' ideas
to communicate in a group ( 5 statements)
to convey core opinion of complex ideas and plans via talking
to use computer science vocabulary
to write scientific reports (4 statements)
to read papers and documentation (4 statements)
proper writing
document formatting
information visualization

draw from this analysis is that even students who are nearing graduation are unaware of the role that engagement, disposition and temparament play on their future workplace life and career development. We conclude that student stakeholder elicitation provides important input, but needs to be complemented with employer and academic perspectives in order to generate complete CoLeaF competencies.
Table 4: Clustering of 4th year student stated competencies

\begin{tabular}{|c|c|c|}
\hline \multirow[t]{2}{*}{ Competency Learning Component } & \multicolumn{2}{|c|}{ Number of } \\
\hline & $\begin{array}{l}\text { compe- } \\
\text { tencies }\end{array}$ & $\begin{array}{l}\text { unique } \\
\text { comp. }\end{array}$ \\
\hline Knowledge & 36 & 25 \\
\hline Subject-related professional skills & 108 & 35 \\
\hline Generic professional skills: & & \\
\hline Teamwork & 61 & 19 \\
\hline Communication & 51 & 20 \\
\hline Problem solving & 14 & 8 \\
\hline Information finding & 4 & 2 \\
\hline Other generic skills & 9 & 6 \\
\hline Self-regulatory skills: & & \\
\hline $\begin{array}{l}\text { Planning, time management } \\
\text { and stress handling }\end{array}$ & 41 & 9 \\
\hline Learning and studying & 26 & 5 \\
\hline Self-reflection & 18 & 4 \\
\hline Self organisation, responsibility & 15 & 9 \\
\hline Self-evaluation and limitations & 6 & 5 \\
\hline Dispositions & 15 & 15 \\
\hline In total & 404 & 162 \\
\hline
\end{tabular}

Table 5: Aggregated 4th year student competencies

\begin{tabular}{|l|}
\hline Develop and maintain programs and systems \\
Analyze and solve problems algorithmically \\
Be versatile in programming \\
Work in groups in different settings \\
Communicate orally and in writing in different settings \\
Identify, analyze and solve problems in different settings \\
Retrieve information in an effective way \\
Plan and use your time wisely in a healthy way \\
Learn independently and efficiently \\
Reflect on your work, studies, future etc. \\
Organize your work and take responsibility \\
Evaluate yourself and identify what you can improve \\
and your limitations \\
\hline
\end{tabular}

4.1.2 Competency Statements from First Year Students. Having asked fourth year students how they perceived the competencies needed for working life, we wondered if one can derive useful competencies even from less experienced students.

To address this issue we use similar data from first year students of the same program and analyse the data in the same way. We have asked all students at their end of their first year of studies, i.e. 20 percent of the five-year program, to suggest competencies. The question was similarly formulated as for the fourth year students, but instead of the most important competencies that the students think that they had developed during their studies, we asked for the most important competencies that the students think that they should develop during their studies. 142 students answered, and 133 of them gave us permission to use their answers in research. These 133 students stated 639 competencies, about 5 per student, of which 175 were classified as unique. 
We used the same method to analyse the data from the first year students. The result of the clustering in eleven clusters can be found in Table 6. We identified three sub-clusters in the subjectrelated professional skill cluster and formulated aggregated student perceptions of competencies, see Table 7.

Table 6: Clustering of first year student stated competencies

\begin{tabular}{|c|c|c|}
\hline \multirow[t]{2}{*}{ Competency Learning Component } & \multicolumn{2}{|c|}{ Number of } \\
\hline & $\begin{array}{l}\text { compe- } \\
\text { tencies }\end{array}$ & $\begin{array}{l}\text { unique } \\
\text { comp. }\end{array}$ \\
\hline Knowledge & 50 & 29 \\
\hline Subject-related professional skills & 157 & 39 \\
\hline Generic professional skills: & & \\
\hline Teamwork skills & 100 & 12 \\
\hline Communication skills & 46 & 12 \\
\hline Problem solving skills & 31 & 5 \\
\hline Other generic skills & 4 & 4 \\
\hline Self-regulatory skills: & & \\
\hline Planning, time management & 87 & 11 \\
\hline Self-learning and independence & 48 & 10 \\
\hline Self-reflection & 29 & 7 \\
\hline Self discipline, responsibility & 21 & 5 \\
\hline Dispositions & 66 & 41 \\
\hline In total & 639 & 175 \\
\hline
\end{tabular}

Table 7: Aggregated first year student competencies

Develop and maintain programs and systems of high quality

Analyze and solve complex computational problems

Develop and manage large IT systems

Work in groups in different settings

Communicate orally and in writing in different settings

Formulate, analyze and solve problems in different settings

Plan and use your time wisely in a structured and healthy way

Learn independently and efficiently

Learn from mistakes and hare knowledge

Reflect on and evaluate your work

Reflect on ethics, gender, and inclusiveness

Show self-discipline and take responsibility

4.1.3 Comparison of Student Statements with Definition of Educational Program. Through our analysis we have identified the set of competencies and dependent-competencies that the students think are most important in regard to their education and future careers.

How do these competencies compare to the competency and outcome framed goal definitions of the educational program, as codified in the official program objectives [82]. There are ten program objectives, of which four refer exclusively to knowledge areas, however, the other six are formulated in a manner similar to the competencies we have been discussing in the remainder of this report:

(1) Have the ability to independently define and solve computerrelated construction problems.
(2) Have the prerequisites for successful work in international and multidisciplinary project groups which consist of people from both technical and non-technical backgrounds. This includes the ability to orally, and in writing, present as well as argue in Swedish and English.

(3) Independently analyse and adopt a standpoint on economical, societal, environment-related and ethical consequences of computer science applications, and to design systems concerning this.

(4) Through self-development, retain one's professional abilities during a professional career.

(5) Have prerequisites and abilities to participate in and develop the practices which are applied in industry, administration, and academic research.

(6) Follow and promote the discussion concerning technology in society.

We have been able to link all fourth year student stated competencies, including the dispositional and several knowledge-focused competencies, to these six program objectives, and they seem to cover the program objectives quite well. We did not find any competency that did not fit into the broader definition provided by a high level program objective.

If we formulate the program's comprehensive competency of work as a computer science engineer in terms of a set of enabling (depending) competencies, we thus obtain a four level competency hierarchy, representing a precedence graph of competencies as summarised in Table 8.

In exactly the same way we could create a four level competency hierarchy using the first year student competencies, the aggregated competencies of Table 7, the program objectives above, and the program's comprehensive competency, see Table 9.

4.1.4 Discussion. The students were not taught what a "competency" was before they were requested to answer the competency question above. Therefore, it is natural that some answers only contain a knowledge component, see Table 1 . However, these statements were less than $10 \%$ of all student statements.

Even though the number of stated competencies gleaned from first year students (Table 6) is 60\% larger than the number of stated competencies by 4 th year students (Table 4), the number of unique competencies is about the same (only $8 \%$ larger). This might indicate that a point of saturation has been reached. The largest difference between the size of the 1st and 4th year unique competency clusters is that the first year students stated more dispositions (41 compared to 15) but fewer generic professional skills (33 compared to 55). From the 1 st to the 4 th year, the students are exposed to a number generic professional skills, which might put the 4th year students in a better position to identify such skills and distinguish amongst them, as well as experience them as important program competencies. For a first year student it might be easier to imagine dispositions without a true context due to lack of experience in the field.

When looking at the generic professional skills mentioned by the 4 th year students, see Table 8 , there are a few things worth discussing related to the different skills. First the communication skills mentioned, see Table 3, are very much focused on oral and human communication, and not so much communication mediated by technology or communication with technology. One reason for 
this might be that some computer science students see technology as a neutral medium for communication [61], that does not affect communication, and therefore do not mention this kind of communication. Moreover, listening is not mentioned as a part of communication and many students seem to focus on information transfer or one way communication from them to others. Moreover, it is interesting to notice that even though the survey was distributed in a Swedish context, many students have stressed communication in English as an important competency that they have acquired during their education.

In terms of teamwork skills, many students expressed that this is a crucial part of their education. It is worth noticing that working in large groups is explicitly mentioned as an important competency acquired, and that learning how to work in diverse teams has been especially appreciated as a competency. Previous research in Sweden reports, however, on students who really do not see the development of competencies such as intercultural communication and working in diverse teams as relevant to their education or discipline [77]. This research also shows that the area of computer science is experienced by many students as only being about "solving problems and programming" which can be linked to a "systemic problem solving perception" of the discipline. However, our earlier research has also shown that students' perceptions of what is relevant can be shaped and expanded during their education.

When interpreting the generic skills stated, we notice that googling, "to Google in an Effective Way" or searching the internet is mentioned as a crucial skill that they have developed during their education. None of the students mention other means of development of information skills such as through books, or other kinds of literature, which reflects a trend among students, and a value system inherent in the culture of the educational programme.

When looking at the self-regulatory skills mentioned by the students, planning seems to be one of the most appreciated skills developed together with self directed learning, and especially to learn fast. Planning and learning were given as examples in the task description, which might have influenced the students.

We were interested in whether the student stated competencies missed important parts of the program objectives, whether they addressed all program objectives, and whether there are student stated competencies that not at all fall within the program objectives. The competencies in Table 8 show that all program objectives indeed were addressed by the students. Moreover, every student stated competency, even each disposition, could in a reasonable way be associated with one of the program objectives. This exercise thus indicates that, in the case we consider here, the program director, who defines the program objectives, and the 4th year students agree to a large extent on which competencies a student should possess after completing the program. The level of agreement can be taken as an important indicator of program coherence and alignment of student conceptions with programme leadership expectations [51].

For the first year student stated competencies, we used the same method to create the program competencies in Table 9. The competency set is similar but not identical to the program competencies based on the 4th year student statements. At least for this program, the program competencies picture based on the first year students is as useful as the program competencies picture based on students at the end of their education.
4.1.5 Summary. This case study demonstrates how students' reflections on competency can be used to derive thematic clusters concerning how students see the competencies they are, or think they are developing. While this does not in itself provide a complete picture of competencies we argue that student expectations and perceptions are an important aspect of eliciting competency definitions from engaged stakeholder groups. Table 8 shows the correspondence between the program objectives and the student-stated competencies. Interestingly, even the environmental and ethical objective elicits corresponding student-stated proto-competencies. There is a body of research which suggests that Engineering students loose interest in social impact and related topics over time [20], however, our results show the opposite. What these results suggest is that exploring student perceptions of competence is an important factor in program assessment and in formulating culturally relevant competency statements to capture local conditions.

\subsection{Deriving Competencies from Discipline Documentation}

An alternative case study approach is to derive competencies from the documentation for an existing course, program or set of knowledge-units. The difficulty is that these existing descriptions for a course, degree-program or knowledge units have been developed over time, typically using traditional outcomes language focused on knowledge attainment and/or use. Consequently they include implicit competencies, rather than explicit ones. As such, a naive mapping of knowledge units or topics in a course or degree program would not normative map directly to the CoLeaF framework. This section presents an exploration of the explicit and implicit competency components as an example of deriving competency statements from discipline documentation.

An illustration of utilising CoLeaF can be drawn at many levels, from a tertiary/ disciplinary-level down to learning-unit levels or below. From a practitioner's perspective, the idea that the purpose of one's tertiary education, or even of a particular course is the development of contextually-situated professional competencies is immensely practical. This section presents an example of deriving CoLeaF statements at a course/ class level, specifically for a software engineering topic common to computer science education: Development of competency in software testing [36]. The specific context was a software testing module comprising approximately $1 / 2$ of a 14-week (semester) class for an undergraduate degree program in Software Engineering from the United States. The student work on developing testing competency was spread out across the semester. The work included homework focused on specific skill and knowledge development, and application to a course project begun at mid semester, and then completed in the last weeks of the course.

Software testing is a well-documented mandatory topic in software engineering, and is routinely part of a tertiary education program in software engineering $[17,39,69]$. Software testing has significant cognitive (knowledge) components, such as Black-box test design, white-box test design, unit, integration, system, test design, etc.. However, it is more often characterised as a skill [92], due to the integrated nature of testing knowledge components, and then the notion that software testing is the performance of a 
Table 8: A competency hierarchy based on 4th year student's experience of competencies

To work as a computer science engineer a Master of Computer Science and Engineering should:

Independently define and solve computer-related construction problems.

Develop and maintain programs and systems

the theoretical foundation on which programming is based (knowledge)

[24 sub-competencies omitted]

Analyse and solve problems in an algorithmic manner

advanced algorithms and data structures (knowledge)

complexity theory (knowledge)

address problems in an algorithmic manner

design, implement and analyse algorithms and data structures

Be versatile in programming

pick up new languages/systems/frameworks

write code in several programming languages and many different contexts

program using functional programming

feel comfortable with math and programming (disposition)

know the importance of knowing the fundamentals of how a software (like a game engine) works (disposition)

never give up on solving a problem (disposition)

[4 competencies omitted]

Have the prerequisites for successful work in international and multidisciplinary project groups which consist of people from both technical and non-technical backgrounds. This includes the ability to orally, and in writing, present as well as argue in Swedish and English.

Communicate orally and in writing in different settings

[15 sub-competencies omitted]

Work in groups in different settings

work in an international group; work in a bigger team of developers; collaborate; plan work in project groups;

discuss/reflect in groups; organise a larger project with several members; analyse other people's work;

work with people that are very different from you/that you are not comfortable working with/having different

preferred methods of how to tackle a problem, bringing forth your own ideas in a collaborative project;

identify which role I have in a group dynamic; handle conflicts; lead teamwork; divide and delegate work

communicate in a group (communication skill)

lay out work beforehand (planning skill)

manage projects (other generic skill)

be active and supportive in teamwork (disposition)

hear everybody out, finding a way to work with people that don't match you personally (disposition)

accept multiple solutions to the same problem (disposition)

independently analyse and adopt a standpoint on economical, societal, environment-related and ethical consequences of computer science

applications, and to design systems concerning this.

Reflect on environmental sustainability with respect to computer science

Reflect on ethical issues as a computer science professional

Show ethical awareness (disposition)

through self-development, retain one's professional abilities during a professional career.

Learn independently and efficiently

Reflect on my own development

Identify when I need to learn something on my own, when I need to repeat or rehearse something

have prerequisites and abilities to participate in and develop the practices which are applied in industry, admin, and academic research.

Identify, analyse and solve problems in different settings

Plan and use your time wisely in a healthy way

Organise your work and take responsibility

Evaluate yourself and identify what you can improve and your limitations

Show a scientific way of thinking (disposition)

Be confident that I have learned a wide variety of skills and can approach different kinds of problems (disposition)

Show desire and ability to pursue my own projects (disposition)

follow and promote the discussion concerning technology in society.

Explain technology; speak in public; get your point across; retrieve information in an effective way

Think critically

Be curios about new technologies (disposition)

Keep in touch with current research and technological development (disposition) 
Table 9: A competency hierarchy based on first year student stated competencies

To work as a computer science engineer a Master of Computer Science and Engineering should:

have the ability to independently define and solve computer-related construction problems.

Develop and maintain programs and systems of high quality

[39 sub-competencies omitted]

Analyse and solve complex computational problems

theoretical computer science, such as algorithms, data structures, and logic (knowledge)

decompose computational problems

understand, analyse and solve problems of computational or mathematical character

solve complex problems with a computer in a flexible and efficient way

be certain that you can solve problems by putting known problems in new contexts (disposition)

Develop and manage large IT systems

[13 sub-competencies omitted]

have the prerequisites for successful work in international and multidisciplinary project groups which consist of people from both technical and non-technical backgrounds. This includes the ability to orally, and in writing, present as well as argue in Swedish and English.

Communicate orally and in writing in different settings

[12 sub-competencies omitted]

Work in groups in different settings

cooperate; cooperate in programming and software development;

show leadership; divide the work in a group; motivate others to work;

work efficiently in groups/with other people; work in both small and large groups;

handle different types of group dynamics;

solve conflicts in a group; work inclusive in a group; compromise;

present to your group

independently analyse and adopt a standpoint on economical, societal, environment-related and ethical consequences of computer science applications, and to design systems concerning this.

knowledge of sustainability

Reflect on ethics, gender, and inclusiveness

reflect on ethical issues and how they influence your work

reflect from a gender perspective

reflect on how to be inclusive

Show ethical awareness (disposition)

through self-development, retain one's professional abilities during a professional career.

Learn independently and efficiently

Learn from mistakes and to share knowledge

Constantly be open to changes and continuous self-development (disposition)

Be conscious of your actions and how to improve yourself (disposition)

Be ambitious and put high demands on your work (disposition)

Be willing to develop your competencies, not be content with what you have (disposition)

have prerequisites and abilities to participate in and develop the practices which are applied in industry, admin, and academic research.

Formulate, analyse and solve problems in different settings

Plan and use your time wisely in a structured and healthy way

Show self-discipline and take responsibility

Reflect on and evaluate your work

Use your knowledge in practice

Work according to a specification and plan

follow and promote the discussion concerning technology in society.

Communicate your ideas so that others will understand

Use correct technical special language when speaking about your area

Communicate your product or research to different target groups

Retrieve information in an effective way

Think critically and show a critical approach (disposition)

Show a scientific approach based on facts in both your communication and your work (disposition) 
series of inter-related quality activities that touch upon assessing and responding to the quality of a particular software component. The skill aspects expected of a software engineer are illustrated in Table 10.

Table 10: Table of Testing-related Skill Areas from [92]

\begin{tabular}{|l|}
\hline Software Engineering Lifecycle Skill Areas and Skills: \\
Software Testing Skills: \\
\hline Software Test Planning \\
Software Testing Infrastructure \\
Software Testing Techniques \\
Software Testing Measurement and Defect Tracking \\
\hline Software Engineering Crosscutting Skill Areas: \\
Software Quality Skills \\
\hline Software Quality Management (SQM) \\
Reviews (review, walkthrough, inspection) \\
\hline
\end{tabular}

The Software Engineering 2014 (SE2014) report documents the community agreement on what comprises tertiary education expectations for software testing. These are presented in Table 11. In this table, the software testing topics deemed essential (E) in SE2014 that are intended in the course are listed, and each topic is denoted at knowledge(k), comprehension(c) or application(a) level [69]. While some of these expectations are at the 'comprehension' level (c), most of these topics are expected to be learned at the 'application' level (a), "Using learned material in new and concrete situations. For example, using information, methods, concepts, and theories to solve problems requiring the skills or knowledge presented." From a competency perspective, while the language utilised is that of a cognitive skill, the expectation, at least for the course, is for students to actually perform these skills in an appropriate context implies both skill and dispositional outcomes.

Table 11: Table of Testing Terms [69]

\begin{tabular}{|l|l|c|c|}
\hline Reference & & $\mathbf{k , c}, \mathbf{a}$ & ED \\
\hline VAV.rev.1 & Personal reviews & $\mathrm{a}$ & $\mathrm{E}$ \\
\hline VAV.rev.2 & Peer reviews & $\mathrm{a}$ & $\mathrm{E}$ \\
\hline VAV.tst.1 & $\begin{array}{l}\text { Unit testing and test-driven devel- } \\
\text { opment }\end{array}$ & $\mathrm{a}$ & $\mathrm{E}$ \\
\hline VAV.tst.2 & $\begin{array}{l}\text { Exception handling (testing edge } \\
\text { cases and boundary conditions) }\end{array}$ & $\mathrm{a}$ & $\mathrm{E}$ \\
\hline VAV.tst.3 & $\begin{array}{l}\text { Coverage analysis and structure- } \\
\text { based testing }\end{array}$ & $\mathrm{a}$ & $\mathrm{E}$ \\
\hline VAV.tst.4 & $\begin{array}{l}\text { Black-box functional testing tech- } \\
\text { niques }\end{array}$ & $\mathrm{a}$ & $\mathrm{E}$ \\
\hline VAV.tst.5 & Integration testing & $\mathrm{c}$ & $\mathrm{E}$ \\
\hline VAV.tst.6 & $\begin{array}{l}\text { Developing test cases based on use } \\
\text { cases andor user stories }\end{array}$ & $\mathrm{a}$ & $\mathrm{E}$ \\
\hline CMP.tl.3 & Unit testing tools & $\mathrm{c}$ & $\mathrm{E}$ \\
\hline \hline
\end{tabular}

Following the SE2014 intent, the competencies involved in the course centre can be simplistically expanded as:

- Knowledge of test vocabulary, and how to develop tests using several types of code, e.g., patterns for boundary-value, domain, path and other styles of generating test values for different types of code.

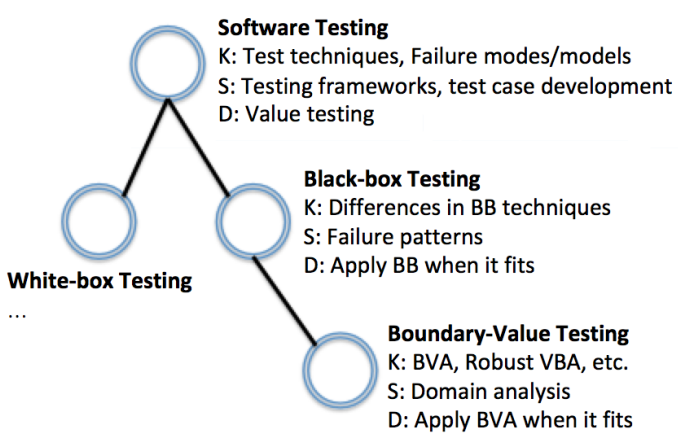

Figure 8: Competency hierarchy fragment for software testing concepts

- Skill centred around concepts of test planning, establishing and utilising test infrastructures (e.g. unit testing frameworks, etc.) and introductory testing measurement and defect tracking.

- Dispositions focusing on how students value testing and other software quality interventions - will they design and implement tests for their code when they are not forced to by the context of a testing course?

Using this näive approach, the notion that these software testing competencies are hierarchical is easy to establish. For example, while the topic of 'boundary-value' testing can be considered knowledge, in a proper sense this is not just knowledge, but also related skill and disposition. In this sense, the ability to apply of black-box testing implies a competency in black-box testing: the student mastering of the conceptual, procedural and dispositional knowledge [11] of boundary-value testing.

At another level, the more general 'software testing' competency central to the course can be generalised, that is, subsumed into a broader competency for software systems testing. This would happen by generalising the testing competency to go beyond just software, e.g., to include integrated hardware components, and the competency in Software System Testing would include the competency of Software Testing. Moving down the competency hierarchy would be examining say the application of a particular software testing pattern, such as "Boundary Value Testing."

Figure 8 depicts a fragment of the competency hierarchy for the course. The competency names are somewhat arbitrary, but parallel modules in the course and reflect the vocabulary of the text and course notes. This is however, only a very partial view of the competencies involved in software testing. When seriously considering the "personal qualities causally related to effective performance in an area of work" that "Integrates Knowledge, Skills, and Dispositions" in the professional context of software testing, the preliminary understanding of the competencies depicted in Figure 8 has a number of deficiencies. While the figure accurately represents the hierarchical nature of the concepts, it is not very effective at identifying the integration of the disposition and skills needed to successfully apply the testing concepts listed. Other skills and dispositions need to be considered from among those 
taught, and intended of the learners in the course. This requires an exercise in collapsing and reforming the competency tree in order to more completely identify the core and sub-competencies that are intended of the learners in the course.

Collapsing and reforming the competency tree. Already having a competency tree offers the possibility to find alternative ways to structure the tree. There are multiple approaches, but two key ones are to reconsider the course outcomes and the course intent to better define the competencies already included in the course, and to explore these same sources to find implicit competencies not yet defined.

The process would be to abstract away all but the top competency and collect all knowledge, skill, and disposition components in three sets and then look for potential subsets of learning components that could form a "new" or ill-defined competency/sub competency. Ideally, when contextualised for the course in which these students would be working, these top-level competencies should serve as useful learning objectives for the course, as they would aspirationally describe the competencies that the learning experiences are intended to help develop. The current stated course objectives related to Software Testing should also convey that intent. In this case, the stated course outcomes were:

(1) Develop and apply appropriate tests for object-oriented software designs

(2) Appreciate the need for designing and testing in effective software development

Which leave significant implications as to what is meant, and what K-S-D components are expected to be demonstrated by students. Making explicit the implied K-S-D components in the context of the disciplinary expectations should result in more useful, well (or better-) formulated competency statements useful for the course.

Examining the course material and intent, the first of these outcomes statements includes the following software testing skills and knowledge from Figure 11: unit testing and an introduction to testdriven development (VAV.tst.1), patterns for testing edge cases and boundary conditions (VAV.tst.2), coverage analysis and structurebased testing (VAV.tst.3), black-box functional testing techniques (VAV.tst.4) and an introduction to integration testing (VAV.tst.5). But the anecdotal evidence of students leaving the course suggested best-practice outcomes of the course in fact had students leaving the course employing, and prepared to effectively employ these practices on their own projects and in the workplace. They had begun to, and through their experiences reported back from their internships and occasionally in other university projects demonstrated "a personal commitment to quality" [40].

When thinking about the goals of the course, applying CoLeaF serves as a structure to support thinking out the synthesis of these fragments of knowledge, skill and disposition statements in the context of the course material. In this case, as the course has been run multiple times, this can include not just the hopes of the instructor, the course outcomes and related domain definitions, but also the best-case competencies demonstrated by students exiting the course. These two course outcomes are very broad; the course material that supports setting students up with the foundations for test-driven development, e.g., (VAV.tst.1) where student design test cases prior to writing code, and leveraging the test-case development process to explore aspects and issues of the requirements emerging design. This is the most interesting of the content foci, as it implies disposition, and relates to course outcome (2). Similarly the outcomes, at least aspirationally, hope to provide students with the experience to judge test-case design methods. Success for the course is to have student choose to not just mechanically apply test-case generation techniques, but rather judge between highvalue (or higher-value) tests, and invest in those. Similarly, it also implies that students will choose to design test cases early in the development process and use this to help explore requirements ambiguity.

Again, this exploration of intent of the course implies not just skill in test development, but also skill and the willingness to evaluate the potential of individual test cases to find bugs. The demonstration of this set of skills would want to explore multiple of the test-case generation techniques, successful application of those techniques, good judgement in reducing these test-cases to include the most likely to find bugs, and judicious addition of more test cases when warranted. This type of competency is more related to applied quality, indicating that students not only understand testing, but care enough about the quality of the product under test to leverage well the test techniques and tools they have available. So perhaps the central competency isn't really about testing, but rather about enacting quality.

With these thoughts in mind, a working competency statement for the testing component of the course might look like:

\section{Demonstrate personal commitment to quality software development employing effective software testing tech- niques.}

While still broad, this statement better captures the intent of the testing component of the course - to develop professional competence, including the professional values surrounding software quality utilising the community-agreed mechanism of software testing. While the definition of the content of "effective software testing techniques" is left ambiguous, this material would be obvious in the context of the course syllabus, and similar to other appropriate ambiguities in outcomes language, would also open to shifts as the science and practice of effective object-oriented testing changes.

\subsection{Summary}

This brief examination of competency from curricular documents suggests that the effort involved in developing CoLeaF statements can be useful. The faculty effort in uncovering the implicit competency components from the curricular documents can result in broad statements that better capture the aspirational and demonstrable goals of degree-program/course, etc.

\section{DISCUSSION}

CoLeaF provides a competency model encoding learning products in individuals in the form of performance based metrics grounded in fundamental building blocks. These building blocks are knowledge, skill and disposition, and we posit that these mirror the expectations of the results of education as summarised in the learning theory survey of Krathwohl [56]. In alignment with Krathwhohl, et al., our 
work suggests that it is not the learning components per-se that formulate competencies, which in turn are expressed in performance, but rather the synthesis of these components which empower performance. Here the observation of Pikkarainen [79][pp.628] in regard to the concept of competency is informative.

"Competency is a promising candidate for the product of education because it is something needed in the labour market, or at least is discussed in work and management discourses in addition to educational discourse."

While this formulation is common (e.g., $[67,74,96]$ and others), a number of other approaches have been proposed (e.g., [85]). This work synthesises a broad collection of educational scholarship to address the structure of a competency (e.g., $[71,79])$. For example, it is easy to find both in educational research literature and practitioner parlance a particular debate among education researchers and practitioners. These mixed approaches, and in particular models focused on 'abilities' are common in educational literature [6, 89, 105]. Figure 9 illustrates a U.S. Department of Education 2001 conceptual model that regards competency fundamentally as a combination of skills, abilities, and knowledge where "Competencies, then, are the result of integrative learning experiences in which skills, abilities, and knowledge interact to form learning bundles that have currency in relation to the task for which they are assembled" [105]. These conflicting definitions (e.g., ability vs. disposition) may seem trivial to the casual observer, but their negative impact has been substantial [74, 75, 89, 107].

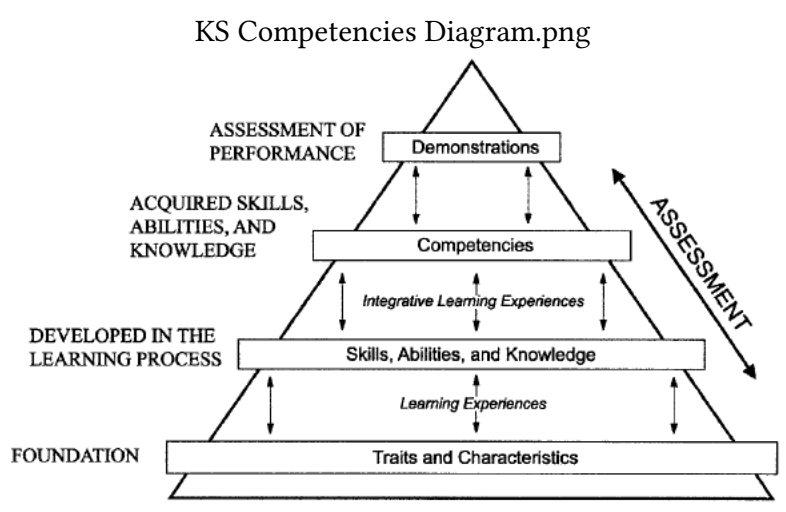

Figure 9: 2001 Competency-based Conceptual Learning Model using 'Abilities' (Source U.S. Department of Education in [105])

This figure suggests, common to much of the competency literature of its day, a model that is incompletely connected to the psychological foundations of learning, specifically the cognitive, psychomotor and affective dimensions [56]. The notion that competencybased education has value, and is important to a more effective approach to educational practice is well founded. E.g., the bundling and unbundling of skills and knowledge "that drives competencybased initiatives among post secondary entities" [105] is not new. That competencies need to be understood with respect to the learner is also consistent with arguments advanced by other authors in the current literature.
Also common in the literature is the view that a competency is best modelled as knowledge and/or skill components that can be considered separate from the associated dispositional component [74]. Our work synthesising other significant scholarly literature suggests that integration is crucial $[6,74,75,89]$. The theoretical underpinning of CoLeaF presented in Section 2 and the consequent model (Section 3) strongly suggests that a well-modelled competency is in fact more than the individual consideration of its knowledge, skill and dispositional components. The CoLeaF framework, while not entirely novel, represents a significant departure from many attempts at applying competency to guide the structure and conduct of education, as well as providing a means for defining educational "product" in the context of the modern utilitarian tertiary education discourse [79]. [pp.622].

Disposition One of the contributions of this work is the integration of disposition into the model. However, like the term 'competency', disposition can also be a misleading concept. In English disposition has two co-existing definitions: the first is administrative, while the second refers to human temperament.

The administrative meaning is the one employed in this and other work related to competency [38, 75, 86, 89]. The fundamental point of departure is that disposition is that "Act or power of disposing or the state of being disposed" where the definition of 'being disposed' is "to place in readiness" or "arrange in an orderly way" [64]. In the context of a competency, a disposition helps to order knowledge and skill in context; to connect the ability (knowledge and skill) with the follow-through of the appropriate behaviour [74]. Disposition is not separate from, but rather intertwined with knowledge and skill $[75,79]$, that in fact when we define a competency well, there is a 'right' or 'better' application of knowledge and skill in some particular context(s). From a learning perspective, disposition is the affective component that deploys skill and knowledge into appropriate action in a specific context. The understanding demonstrated in the performance of a competence is not fundamentally temperamental nor is it a permanent or fixed tendency of a person. Rather disposition relates to the wilful affect of a person to act in a certain manner in particular circumstances.

Here the clarification offered by Pikkarainen [79][pp.628] in regard to the concept of disposition is elucidatory.
"..disposition is often thought of as a normally invisi- ble (or virtual in Greimasian parlance) character of an object, which manifests itself and becomes visible or actual only in some special situation; for example, the fragility of glass, which is invisible and virtual so long as the glass remains intact, but which manifests and actualises when something hits the glass. Here we can see a strong structural equivalence; both competence and disposition are things which at some time are invisible and virtual, and which at some other time are manifested and actualised."

Dispositions are developed over time, and are consequently both learned and learnable [89]. To the extent that a person translates dispositions into habits, and those habits become integrated into their behaviour, does disposition, one's competency, become a more long lasting part of one's personality. E.g., where they affect the subject's temperament in the second English definition. In the same 
way, some dispositions, can, and have to be, unlearned, and replaced by other dispositions. This is often considered to be a natural part of the moral growth of a person as they negotiate their agency in relation to the wilful translation of their values and through the selective application of their skills and knowledge. Hence, disposition as an ingredient of competency is not immutable; the dispositional aspect of competency is always experienced in relation to the value systems of the environments (context) of which the learner is a part. In this sense, disposition is something negotiated through the individual and reflected in their performance in familiar and unfamiliar contexts. While this understanding of disposition is learned, it is also informed by one's character and community and how it is applied can and should shift with one's understanding of the context/circumstances.

To this extent, disposition is clearly connected to the upper levels of Bloom's Affective Domain: Valuing, Organising, etc. The affective domain [56] includes the manner in which we deal with things emotionally, such as feelings, values, appreciation, enthusiasms, motivations, and attitudes. At the upper levels of the affective domain taxonomy is valuing, including acceptance, preference for, or commitment to a value followed by the conceptualisation of that value. These are critical to competency modelling because they relate values to skills and knowledge enacted in context. Internalised values help to determine how we will act, implicitly supporting the ranking of various alternatives considered while formulating the 'right' or 'better' application of knowledge and skills.

The acknowledgement that disposition is an important factor in computing education has been recognised particularly in recent computing curricular documents $[86,96]$.

\subsection{Impact on Curricular Documents}

CoLeaF represents a clear departure from the knowledge-centred approaches common to current computing curricular documents (E.g.,[69, 70, 96]). When these existing curricular documents are used to define graduate competencies the result tends to focus on statements related to graduate performance in specific curricula and knowledge areas, and other important graduate competencies that are not based in the body of knowledge risk being omitted or ignored. This knowledge-centred approach to defining educational goals fundamentally "fails to recognise that student success is dependent on a broader range of fundamental skills, including social-emotional skills, and the application of these "soft" skills" [58].

We suggest that the historical, body of knowledge, approach is flawed from several perspectives.

Agency: Firstly, the approach builds on content, rather than expectations of current and future agency as an individual develops and pursues a career. The computing discipline has a deeply rooted engineering tradition [98] that emphasises the ability of professionals to apply knowledge and skill well in various contexts. This includes their ability to recognise the context they are working in, and to be ethical agents in their workplace and society. Wellmodelled competencies encourage breadth of learning - to learn not just teach academic knowledge, but also the skills to apply their knowledge, the disciplinary skills to enable their application, including the disposition to apply them appropriately in the context of the work being conducted. As suggested in the case-studies presented in Section 4, this breadth includes understanding the depth of knowledge, skill and disposition needed, as well as the lifelong learning skills that are needed for success beyond the classroom.

Breadth: Secondly, a focus on knowledge runs the risk of omitting other types of professional competency such as communication, teamwork and resolving intercultural issues in a given context. Many of the higher-order problem-solving, analysis, design, and development skills needed in computing are reliant on effective communication and teamwork. As such they are reliant on dispositional knowledge, as well as the integration of knowledge, skill and disposition that learning theory presented in Section 2 suggests is central to an effective competency-based approach.

Mindset: Thirdly, the knowledge-focused approach tends to over-focus on two, rather than all three foundations to a competency. There is an 'engineering mindset' applicable to computing that includes understanding and accepting the ambiguity involved with real human problems and objectives, or the humanity of the people served by technology [37]. Rather than encouraging students to develop these competencies, knowledge-focused approach encourages the notion that people's "abilities are carved in stone". In contrast, a competency-based approach encourages growth mindset with a belief that all students can learn and continue to improve [58]. This is particularly critical when people can view dispositions themselves as being fixed, and unchanging, perpetuating traditional roles, cultural norms and power dynamics that do not support inclusiveness and cultural responsiveness.

These areas of improvement will not be immediately resolved by adoption of CoLeaF or other forms of competency modelling. While CoLeaF provides a structured framework for modelling, the many benefits of competency-based education [58, 72] can only be realised by individual programs adopting a competency-based approach in defining the aspirations of their degree programs, and then, like other outcomes-based approaches to education redevelop the course content and assessment to focus on student performance. Hence, this work presents both a challenge and a path to advance the definition of particular program of study and/or curricular documentation of the goals of degree programs

This study supports the CC2020 work focusing future international curricular documentation revision to take on a competencybased approach to describing computing disciplines. Our work proposes a new methodology which draws extensively on key stakeholder groups. To elicit relevant and sustainable graduate competencies data should be collected via interviews, focus groups and surveys. This data can then be analysed using a variety of qualitative techniques $[9,100]$.

To illustrate how this process might result in competency statements we explored data collection and analysis using case studies. In Section 4.1 we have utilised a grounded theory inspired approach with influences from phenomenography [60] to cluster student data collected in two surveys and relate student statements to competencies in a degree program. In Section 4.2 we presented a course-level competency derivation, and illustrated the derivation 
of competency statements utilising existing discipline and course documentation.

Developing competencies is not an easy process, partly due to the fact that different stakeholder groups take different perspectives. Employers, students and academic staff all have their own unique view of the goals of education [66], and also the competencies needed to practice the various computing professions. In addition we can ask, what does society at large demand, and what constitutes professionalism and quality when we discuss competency frameworks [79]?

\subsection{Relating Competencies to Outcomes}

For competency modelling to be useful for computing education, it is essential that there be an effective bridge to outcomes assessment [46]. When examining issues related to competency modelling, this is in fact one of the issues that has been prevalent in the literature [8]. Outcomes assessment, both at the degree-program and course level are essential to the quality management of effective educational processes. In current practice, the context of most outcomes assessment in computing is focused primarily on cognitive knowledge and skills related to computing (e.g. examine the definition of learning outcomes enshrined in the Bologna Process [79]). But "Professional skills and attitudes form an increasingly large part of the requirements of computer science graduates. Students are assessed on their knowledge and cognitive skills but not on the attitudes that will lead them to practice in the workplace what they have been taught in the classroom" [40]. Hence the assessment of disposition, and particularly student performance of the integration of disposition, skill and knowledge suggested by the CoLeaF framework appears to be a significant improvement for the definition of outcomes at different levels of the educational structures.

Competencies can, as the two case-studies presented in Section 4 suggest, be developed at both the program-of-study and the individual course level. The case studies indicate, to no surprise, that significant investment into uncovering the implicit competency components and to clearly restate the competency is needed. This process entails, we argued in Section 2.5, to consider the different stakeholders, society, industry, and the students, as well as different values for mankind. Thus, we view it as a central competency for a computing professional to be able to critically engage with a particular ethos - for instance as an approach to the software and systems development work [38, 40].

To measure whether a student has in fact developed appropriate competence requires assessment of more than just knowledge and skill - it involves the attitudes and values. Using CoLeaF to define competence outcomes carries with it significant potential in improving the value of outcomes assessment work. The aspiration for competency outcomes is to contribute to prompting instructors to explicitly develop integrated knowledge, skill and disposition in their students. By explicitly formulating these competency outcomes and communicating them to students, the potential arises for students to explicitly develop a better lexicon for the ethos expected of computing processionals. Similarly, the potential advantages for using CoLeaF for outcomes assessment is equally useful. As competence is normally expressed through performance, welldefined competence statements lend themselves to the assessment of integrated knowledge, skill and disposition. This can imply that difficulties in assessment emerge, but can also be expected to result in significant benefits due to a more holistic approach to outcomes.

Many of the issues with competence assessment centre on the assessment of disposition. The literature repeatedly assert that it is much harder to measure dispositional performance, "partly because there are very few validated assessment instruments but also because students can tell which responses will be rewarded or penalised and answer accordingly" [40]. Similarly, only in rare occasions dispositions can be assessed directly, but rather lend themselves to being assessed indirectly [38]. Other difficulties with disposition outcomes can be identified as well. "Instructors face a dilemma: on the one hand they are uncomfortable with processes that can be seen to judge their students' worth, but on the other hand they are constrained to ensure the moral sensibility of their professional graduates" [31]. This tension is central to understanding the purpose(s) of computing education [65] and instructors' roles therein.

While a competency-based approach to outcomes assessment presents these and other difficulties, such an approach brings with it several significant advantages. The integrated approach suggested by CoLeaF places integrative concepts, such as the need to take the development of professional qualities very seriously at the forefront in designing and deploying computing curricula. The critical importance of realising this linkage is emphasised in numerous studies and reports [40, 59, 63, 83, 87]. However, one of the most critical advantages of a competency-based approach to outcomes is the integration of ethics into curricular delivery [83]. While disposition remains a challenge of outcomes assessment, the advantage is that contextually-situated performance always reflects and helps shape the learner's moral outlook and bridges gaps between content learning and professional skill and disposition development [38, 83].

Similarly, competency modelling in support of outcomes also sets up a situation that pulls the documented and assessed curricular and course intent closer to language relevant to industry. One of the leading issues in realising professional education is addressing the longstanding disconnect between academic program practice and industry needs for learners [11, 15, 54, 102]. Competency modelling provides a structured way to document this, and when employed in a degree program, help employers and students recognise that the graduate has them. In all, documenting outcomes as integrated competencies makes these links more explicit, and thus easier to communicate, assess, teach and learn.

\subsection{Connection to Sound Educational Philosophy}

Lastly, there is a strong argument that competence is fundamentally belongs at the core of education and sound educational philosophy $[63,81,91]$. In a sense, competence development is "a useful theoretical tool when we try to understand the basic structure of education" [79]. It is not that competence is a part of education, it in fact defines it:

We can therefore define education, or rather teaching, as an attempt to bring about changes in someone's competence. How then can this change happen? Competences do change, but what is the mechanism 
whereby this happens and how could it be controlled. ... [T] he change of competence through the subject's own action, is the activity area of education, and it is traditionally called learning [79].

In this way, well-formulated competency definitions are not just supportive of outcomes assessment in computing education with useful benefits, rather competencies are actually a philosophically and methodologically sound approach to computing education. They are at the core of what computing educators do, and the sooner that computing educators will acquire more tools for our teaching [47] and encourage actualising students' performance in their own environments. Expansion of these findings to full programs, and the methods and exercises needed to develop CoLeaF statements is beyond the scope of this work.

\subsection{Recommendations}

CoLeaF establishes a structure for consistent approach to exploring competency as a means of modelling both aspirational and performative goals of degree programs. In a broader context we propose that disciplinary areas employ a structured approach to collecting and analysing data to establish a collection of graduate competencies relevant to a disciplinary area within computing, such as those defined by the established bodies of knowledge.

We propose utilizing CoLeaF or other structured approach to defining graduate competencies. We recognize that this is a substantial and important departure from prior practice in regard to defining graduate competencies. Existing curricular documents define a body of knowledge, often in conjunction with recommendations about the centrality of that content with regard to the discipline, and include an indication of the amount of effort to be devoted to the topic (usually defined in terms of a metric of time such as the credit hour). This content-centred approach incompletely defines and consequently leaves unassessed the actual goals of students' educational programs. Such incomplete requirements sets up computing degree programs to fail to meet their stakeholders' needs, an issue often reported in the literature [83, 102]. By taking a well-structured approach (like CoLeaF) to defining graduate competencies, program staff, curriculum developers and curriculum stakeholders will all have better opportunities to frame and assess their aspirational and performative goals in terms that reinforce the richness of effective computing educational programs.

\section{CONCLUSION}

We have proposed a revised definition of competency rooted in the scholarly education and computing literature. This work defines competency as "The personal qualities causally related to effective performance in an area of work," where an individual competency integrates Knowledge, Skills, and Dispositions in a professional Context. This formulation appears unique, in that it suggests a different, more unified view of the integration of \{Knowledge + Skill + Disposition $\}$ and explicitly layers the professional context as an element that should remain explicit, rather than implicit. One of the major contributions of this work is the view of a competency as being something more than the sum of it's components; and additionally as a virtual or invisible characteristic that emerges in performance in relation to a disciplinary challenge.
This paper provides a foundation for further work regarding capturing educational learning goals spanning from the specific to the holistic. It provides a comprehensive analysis of the research establishing a case for competencies and their use in computing education, outlining a significant body of relevant education and computing literature on competencies, competency models, and the relevant theories involved. It presents the Competency Learning Framework (CoLeaF) and how it can be used as a tool to significantly improve the integration of competency concepts into computing education. Case-studies serve the dual purpose of informing the development of CoLeaF, and providing examples of the construction of concrete examples of context specific competency descriptions.

An open question is the application of CoLeaF for curricula purposes. One obvious application of CoLeaF is as a means to specify competencies in specific contexts, for example, a degree curricula definition at an educational institution, whereas its applicability in capturing competencies in more abstract settings remains to be investigated. Another potential use is to specify a set of required competencies as entry conditions to education degree programmes or individual course units. Concerns regarding the consequences of thus possibly controlling and constraining individuals in their freedom, autonomy, and agency in their process of developing as a person clearly emerge in conjunction with this type of usage.

\section{REFERENCES}

[1] Steve Alsop. 2005. Beyond Cartesian Dualism: Encountering Affect in the Teaching and Learning of Science. Vol. 29. Springer Science \& Business Media, Berlin, Germany.

[2] Massimo Amadio. 2013. A rapid assessment of curricula for general education focusing on cross-curricular themes and generic competencies or skills. Paper commissioned for the Education for All Global Monitoring Report 2013-2014, Teaching and Learning: Achieving Quality for All. UNESCO/International Bureau of Education, Geneva.

[3] Lorin W. Anderson, David R. Krathwohl, Peter W. Airasian, Kathleen A. Cruikshank, Richard E. Mayer, Paul R. Pintrich, James Raths, and Merlin C. Wittrock. 2001. A taxonomy for learning, teaching, and assessing: A revision of Bloom's taxonomy of educational objectives, abridged edition. White Plains, NY: Long$\operatorname{man}(2001)$.

[4] Michael Armstrong and John F Lorentzen. 1996. A handbook of personnel management practice. Kogan page, London, UK.

[5] David Paul Ausubel, Joseph Donald Novak, and Helen Hanesian. 1968. Educational psychology: A cognitive view. Vol. 6. Holt, Rinehart and Winston, New York, NY, USA.

[6] Ronald Barnett. 1994. The Limits of Competence: Knowledge, Higher Education and Society. Open University Press, Bristol, PA, USA.

[7] Jonathan Baron. 1985. Rationality and intelligence. Cambridge University Press, Cambridge, UK.

[8] Ilse Baumgartner and Venky Shankararaman. 2013. Actively linking learning outcomes and competencies to course design and delivery: experiences from an undergraduate Information Systems program in Singapore. In Proceedings of the 2013 IEEE Global Engineering Education Conference. IEEE, Berlin, Germany, 238-246.

[9] Anders Berglund, Mats Daniels, and Arnold Pears. 2006. Qualitative Research Projects in Computing Education Research: An Overview. Australian Computer Science Communications 28, 5 (2006), 25-34.

[10] Harm Biemans, Renate Wesselink, Judith Gulikers, Sanne Schaafsma, Jos Verstegen, and Martin Mulder. 2009. Towards competence-based VET: dealing with the pitfalls. Fournal of Vocational Education \& Training 61, 3 (Sept. 2009), 267-286. https://doi.org/10.1080/13636820903194682

[11] Stephen Billett. 2009. Realising the educational worth of integrating work experiences in higher education. Studies in Higher Education 34, 7 (Nov. 2009), 827-843. https://doi.org/10.1080/03075070802706561

[12] Morten Blomhøj and Tomas Højgaard Jensen. 2007. What's all the Fuss about Competencies? In Modelling and Applications in Mathematics Education, Werner Blum, Peter L. Galbraith, Hans-Wolfgang Henn, and Mogens Niss (Eds.). Vol. 10. Springer US, Boston, MA, 45-56. https://doi.org/10.1007/978-0-387-29822-1_3

[13] Benjamin S. Bloom. 1956. Taxonomy of educational objectives. Vol. 1: Cognitive domain. New York: McKay (1956), 20-24. 
[14] Hilda Borko, Dan Liston, and Jennifer A. Whitcomb. 2007. Apples and fishes: The debate over dispositions in teacher education. Sage Publications, Los Angeles, CA, USA.

[15] Eric Brechner. 2003. Things They Would Not Teach Me of in College: What Microsoft Developers Learn Later. In Companion of the 18th Annual ACM SIGPLAN Conference on Object-oriented Programming, Systems, Languages, and Applications (OOPSLA '03). ACM, New York, NY, USA, 134-136. https: //doi.org/10.1145/949344.949387

[16] Kathrin Bröker. 2014. Identification and measurement of computer science competencies in the area of software development, software engineering and programming. In ICER '14 Proceedings of the tenth annual conference on International computing education research. ACM Press, Glasgow, Scotland, United Kingdom, 141-142. https://doi.org/10.1145/2632320.2632322

[17] Panuchart Bunyakiati and Chadarat Phipathananunth. 2017. Checking Software Engineering Curricula with respect to SE2014 Curriculum Guidelines. In 2017 International Conference on Management Engineering, Software Engineering and Service Sciences. ACM Press, Wuhan, China, 44-48. https://doi.org/10.1145/ 3034950.3034982

[18] Vivien Burr. 2003. Social constructionism. Routledge, New York, NY, USA.

[19] Margaret Carr, Jane McChesney, Bronwen Cowie, Robert Miles-Kingston, and Lorraine Sands. 2010. Dispositions, disciplines, and marble runs: a case study of resourcefulness. In Proceedings of the 9th International Conference of the Learning Sciences-Volume 1. International Society of the Learning Sciences, Chicago, IL, USA, 215-221.

[20] Erin A. Cech. 2014. Embed social awareness in science curricula. Nature 505 (23 Jan. 2014), 477-478. https://www.nature.com/polopoly fs/1.14549!/menu/ main/topColumns/topLeftColumn/pdf/505477a.pdf

[21] O*NET Resource Center. 2018. https://www.onetcenter.org/

[22] Elaine Chapman. 2003. Alternative approaches to assessing student engagement rates. Practical Assessment 8, 13 (2003), 1-7.

[23] Guy Claxton. 2002. Building learning power: Helping young people become better learners. Vol. 9. TLO, Bristol, UK.

[24] Arthur L. Costa and Bena Kallick. 2000. Discovering \& Exploring Habits of Mind. Association for Supervision and Curriculum Development, Alexandria, VA.

[25] Peter J. Denning. 2017. Remaining Trouble Spots with Computational Thinking Commun. ACM 60, 6 (May 2017), 33-39. https://doi.org/10.1145/2998438

[26] John Dewey. 1922. Human nature and conduct: An introduction to social psychology. New York (1922), 41.

[27] Stuart E. Dreyfus and Hubert L. Dreyfus. 1980. A Five-Stage Model of the Mental Activities Involved in Directed Skill Acquisition. Technical Report ORC-80-2. CALIFORNIA UNIV BERKELEY OPERATIONS RESEARCH CENTER. http: //www.dtic.mil/docs/citations/ADA084551

[28] Carol S. Dweck. 2006. Mindset: The new psychology of success. Ballantine Books, New York, NY, USA.

[29] National Council for Accreditation of Teacher Education. 2006. Professional standards for the accreditation of schools, colleges, and departments of education National Council for Accreditation of Teacher Education, Washington, D.C.

[30] Michael Eraut. 1998. Concepts of competence. Fournal of Interprofessional Care 12, 2 (Jan. 1998), 127-139. https://doi.org/10.3109/13561829809014100

[31] Wendy Faulkner. 2001. The technology question in feminism: A view from feminist technology studies. Women's Studies International Forum 24, 1 (Jan. 2001), 79-95. https://doi.org/10.1016/S0277-5395(00)00166-7

[32] Wendy Faulkner. 2007. 'Nuts and Bolts and People': Gender-Troubled Engineering Identities. Social Studies of Science 37, 3 (2007), 331-356. https://doi.org/10. 1177/0306312706072175 arXiv:https://doi.org/10.1177/0306312706072175

[33] PISA Organization for Economic Co-operation and Development. 2018 Preparing Our Youth for an Inclusive and Sustainable World: The OECD PISA Global Competency Framework. http://www.oecd.org/pisa/ pisa-2018-global-competence.htm

[34] Dominique Foray and Bengt-Åke Lundvall. 1998. The knowledge-based economy: from the economics of knowledge to the learning economy. The Economic Impact of Knowledge (1998), 115-121.

[35] K-12 Computer Science Framework. 2016. http://k12cs.org

[36] Stephen Frezza. 2002. Integrating testing and design methods for undergraduates: teaching software testing in the context of software design. In Proceedings of the 32nd Annual ASEE/IEEE Frontiers in Education Conference. IEEE, Boston, MA, USA, S1G-1-S1G-4. https://doi.org/10.1109/FIE.2002.1158637

[37] Stephen Frezza. 2016. Considering the Engineering Mindset - A Response to Does Engineering Education Breed Terrorists?. In Philosophical and Educational Perspectives in Engineering and Technological Literacy, John Heywood and Alan Cheville (Eds.), Vol. 3. ASEE, 1-7.

[38] Stephen Frezza, Mats Daniels, and Aaron Wilkins. 2019. Assessing Students' IT Professional Values in a Global Project Setting. ACM Transactions on Computing Education Special Issue on Global Software Eningeering Education, TBD (2019), 33.

[39] Stephen Frezza, Sreela Sasi, and Jaehoon Seol. 2003. Report from the trenches applying the seek to BSSE program development. In Proceedings of the 33rd
Annual ASEE/IEEE Frontiers in Education Conference, Vol. 3. IEEE, Boulder, CO, USA, S3C-8-13 vol.3. https://doi.org/10.1109/FIE.2003.1265985

[40] Ursula Fuller and Bob Keim. 2007. Should we assess our students' attitudes?. In Proceedings of the Seventh Baltic Sea Conference on Computing Education Research. ACM, Koli National Park, Finland, 187-190. http://crpit.com/confpapers/ CRPITV88Fuller.pdf

[41] Gesellschaft für Informatik e.V. (GI). 2016. Bildungsstandards Informatik für die Sekundarstufe II. https://dl.gi.de/bitstream/handle/20.500.12116/2350/ 57-GI-Empfehlung-Bildungsstandards-Informatik-SekII.pdf?sequence $=1 \&$ is Allowed $=\mathrm{y}$

[42] Gesellschaft für Informatik e.V. (GI). 2016. Empfehlungen für Bachelor- und Masterprogramme im Studienfach Informatik an Hochschulen [Recommendation for bachelor and masterprogrammes in the field of informatics at universities]. https://dl.gi.de/bitstream/handle/20.500.12116/2351/58-GI-Empfehlungen Bachelor-Master-Informatik2016.pdf?sequence=1\&isAllowed $=y$

[43] Silvia Gherardi. 2000. Practice-based theorizing on learning and knowing in organizations. Sage Publications, Thousand Oaks, CA.

[44] Gerald Grant. 1979. On competence: a critical analysis of competence-based reforms in higher education. Jossey-Bass, San Francisco, CA. 592 pages.

[45] Rom Harré and Grant Gillett. 1994. The discursive mind. Sage Publications, Washington, DC, USA

[46] R.W. Hartel and E.A. Foegeding. 2006. Learning: Objectives, Competencies, or Outcomes? Journal of Food Science Education 3, 4 (May 2006), 69-70. https: //doi.org/10.1111/j.1541-4329.2004.tb00047.x

[47] Terrence Hoffmann. 1999. The meanings of competency. Fournal of European Industrial Training 23, 6 (Aug. 1999), 275-286. https://doi.org/10.1108/ 03090599910284650

[48] Peter Hubwieser and Sue Sentance. 2018. Taxonomies and Competency Models. In Computer Science Education: Perspectives on Teaching and Learning in School (1st ed.), Sue Sentance, Erik Barendsen, and Carsten Schulte (Eds.). Bloomsbury Academic, London, 221-242.

[49] Mizuko Ito, Kris Gutiérrez, Sonia Livingstone, Bill Penuel, Jean Rhodes, Katie Salen, Juliet Schor, Julian Sefton-Green, and S. Craig Watkins. 2013. Connected Learning. BookBaby, Cork. OCLC: 896797842.

[50] Elizabeth A. Jones and Richard A. Voorhees. 2002. Defining and Assessing Learning: Exploring Competency-Based Initiatives. Report of the National Postsecondary Education Cooperative Working Group on Competency-Based Initiatives in Postsecondary Education. Technical Report NCES-2002-175; NCES2002-159. National Center for Education Statistics., Washington, DC. https: //eric.ed.gov/?id=ED473245

[51] Viggo Kann and Anna-Karin Högfeldt. 2016. Effects of a Program Integrating Course for Students of Computer Science and Engineering. In Proceedings of the 47th ACM Technical Symposium on Computing Science Education (SIGCSE '16). ACM, Memphis, Tennessee, USA, 510-515. https://doi.org/10.1145/2839509. 2844610

[52] Declan Kennedy, A. Hyland, and Norma Ryan. 2009. Learning outcomes and competencies. In Best of the Bologna Handbook. Vol. 33. DUZ International, Berlin, Germany, 59-76. https://curriculum.gov.mt/en/ Teachers\%20Learning\%20Outcomes/Documents/Training\%20Material/ Paper-LoS-and-Competences-Bologna.pdf

[53] Thomas R. Koballa Jr and Shawn M. Glynn. 2013. Attitudinal and motivational constructs in science learning. In Handbook of research on science education. Routledge, New York, NY, USA, 89-116.

[54] Karoline Koeppen, Johannes Hartig, Eckhard Klieme, and Detlev Leutner. 2008. Current Issues in Competence Modeling and Assessment. Zeitschrift für Psychologie / Journal of Psychology 216, 2 (Jan. 2008), 61-73. https://doi.org/10. 1027/0044-3409.216.2.61

[55] Matthias Kramer, Peter Hubwieser, and Torsten Brinda. 2016. A Competency Structure Model of Object-Oriented Programming. In 2016 International Conference on Learning and Teaching in Computing and Engineering (LaTICE). IEEE-CS, Mumbai, India, 1-8. https://doi.org/10.1109/LaTiCE.2016.24

[56] David R Krathwohl, Benjamin S Bloom, and Bertram B Masia. 1982. Taxonomy of educational objectives: Book 2 Affective Domain (2 ed.). Longman, London. OCLC: 258048912 .

[57] George D. Kuh. 2009. The national survey of student engagement: Conceptual and empirical foundations. New directions for institutional research 2009, 141 (2009), 5-20.

[58] Nina Lopez, Susan Patrick, Chris Sturgis, Antonia Rudenstine, Dixie Bacallao, Sydney Schaef, Maria Worthen, Dale Frost, Natalie Truong, and Ashley Jones. 2017. Quality and Equity by Design. Technical Report. CompetencyWorks. https://www.inacol.org/wp-content/uploads/2017/10/ CompetencyWorks-QualityAndEquityByDesign.pdf

[59] Daniel R. Lynch, Jeffrey S. Russell, Jeffrey C. Evans, and Kevin G. Sutterer. 2009. Beyond the Cognitive: The Affective Domain, Values, and the Achievement of the Vision. Journal of Professional Issues in Engineering Education and Practice 135, 1 (Jan. 2009), 47-56. https://doi.org/10.1061/(ASCE)1052-3928(2009)135: $1(47)$ 
[60] Ference Marton and Shirley Booth. 1997. Learning and Awareness. Routledge, New York, NY, USA.

[61] Roger McDermott, Mats Daniels, Åsa Cajander, Mats Cullhed, Tony Clear, and Cary Laxer. 2012. Student reflections on collaborative technology in a globally distributed student project. In Proceedings of the 42nd Annual ASEE/IEEE Frontiers in Education Conference. IEEE, Madrid, Spain, 1-6.

[62] Martin Mulder. 2014. Conceptions of professional competence. In International handbook of research in professional and practice-based learning. Springer, Berlin, Germany, 107-137.

[63] Martin Mulder. 2017. Competence Theory and Research: A Synthesis. In Competence-based Vocational and Professional Education. Springer, Berlin, Germany, 1071-1106. https://doi.org/10.1007/978-3-319-41713-4_50

[64] Webster's new collegiate dictionary. 1979. . G. \& C. Merriam Co, Springfield, Mass.

[65] Aletta Nylén, Åsa Cajander, Mats Daniels, and Arnold Pears. 2017. Why are we here?: Student perspectives on the goal of STEM higher education. In Proceedings of the 47th Annual ASEE/IEEE Frontiers in Education Conference. IEEE, Indianapolis, IN, USA. https://doi.org/10.1109/FIE.2017.8190639

[66] Aletta Nylén, Åsa Cajander, Mats Daniels, Arnold Pears, and Roger McDermott. 2017. Why are we here? : Student perspectives on the goal of STEM higher education. In Proceedings of the 47th Annual ASEE/IEEE Frontiers in Education Conference. IEEE, Indianapolis, IN. https://doi.org/10.1109/FIE.2017.8190639

[67] Council of Chief State School Officers. 2013. Knowledge, Skills, and Dispositions The Innovation Lab Network State Framework for College, Career, and Citizenship Readiness, and Implications for State Policy. Technical Report. https://files.eric ed.gov/fulltext/ED542708.pdf

[68] The Royal Academy of Engineering, The Institution of Engineering and Technology, and The British Computer Society. 2009. Engineering Values in IT. Technical Report. The Royal Academy of Engineering, 3 Carlton House Terrace, London. 44 pages. https://www.raeng.org.uk/publications/reports/ engineering-values-in-it

[69] Joint Task Force on Computing Curricula. 2015. Software Engineering 2014 Curriculum Guidelines for Undergraduate Degree Programs in Software Engineering. IEEE Computer Society and the Association for Computing Machinery. https://www.acm.org/binaries/content/assets/education/se2014.pdf

[70] Joint Task Force on Computing Curricula. 2016. Computer Engineering 2016 Curriculum Guidelines for Undergraduate Degree Programs in Computer Engineering. IEEE Computer Society and the Association for Computing Machinery. https //www.acm.org/binaries/content/assets/education/ce2016-final-report.pdf

[71] Honor J. Passow. 2012. Which ABET Competencies Do Engineering Graduate Find Most Important in their Work? fournal of Engineering Education 101, 1 (Jan. 2012), 95-118. https://doi.org/10.1002/j.2168-9830.2012.tb00043.x

[72] Honor J. Passow and Christian H. Passow. 2017. What Competencies Should Undergraduate Engineering Programs Emphasize? A Systematic Review. Journal of Engineering Education 106, 3 (July 2017), 475-526. https://doi.org/10.1002/jee. 20171

[73] James W. Pellegrino and Margaret L. Hilton (Eds.). 2012. Education for Life and Work: Developing Transferable Knowledge and Skills in the 21st Century. National Academies Press, Washington, D.C. https://doi.org/10.17226/13398

[74] David N. Perkins, Eileen Jay, and Shari Tishman. 1993. Beyond Abilities: A Dispositional Theory of Thinking. Merrill-Palmer Quarterly 39, 1 (1993), 1-21. http://www.jstor.org/stable/23087298

[75] David N. Perkins and Shari Tishman. 2006. Learning that matters: Towards a dispositional perspective on education and its research needs. A report prepared for the Spencer Foundation (2006), 43.

[76] Frédéric Perrier and Jean-Baptiste Nsengiyumva. 2003. Active science as a contribution to the trauma recovery process: Preliminary indications with orphans from the 1994 genocide in Rwanda. International fournal of Science Education 25, 9 (2003), 1124

[77] Anne-Kathrin Peters, Waqar Hussain, Åsa Cajander, Tony Clear, and Mats Daniels. 2015. Preparing the Global Software Engineer. In Proceedings of the 10th International Conference on Global Software Engineering. IEEE-CS, Ciudad Real, Spain, 61-70. https://doi.org/10.1109/ICGSE.2015.20

[78] Jean Piaget. 1937. La construction du réel chez l'enfant. Delachaux $\mid \&$ Niestle, Oxford, England.

[79] Eetu Pikkarainen. 2014. Competence as a Key Concept of Educational Theory: A Semiotic Point of View. Journal of Philosophy of Education 48, 4 (Nov. 2014), 621-636. https://doi.org/10.1111/1467-9752.12080

[80] Andrew Porter, Jennifer McMaken, Jun Hwang, and Rui Yang. 2011. Common core standards: The new US intended curriculum. Educational Researcher 40, 3 (2011), 103-116.

[81] John Preston. 2017. Competence Based Education and Training (CBET) and the End of Human Learning: The Existential Threat of Competency. Springer, Berlin, Germany. Google-Books-ID: T7DLDgAAQBAJ.

[82] Degree Programme in Computer Science Programme objectives and Engineering. 2018. https://www.kth.se/student/kurser/program/CDATE/20182/mal?l=en\#
[83] Alex Radermacher and Gursimran Walia. 2013. Gaps Between Industry Expectations and the Abilities of Graduates. In Proceeding of the 44th ACM Technical Symposium on Computer Science Education (SIGCSE '13). ACM, New York, NY, USA, 525-530. https://doi.org/10.1145/2445196.2445351

[84] Ron Ritchhart. 2002. Intellectual character: What it is, why it matters, and how to get it. John Wiley \& Sons, Hoboken, NJ, USA.

[85] Emil Rodolfa, Russ Bent, Elena Eisman, Paul Nelson, Lynn Rehm, and Pierre Ritchie. 2005. A Cube Model for Competency Development: Implications for Psychology Educators and Regulators. Professional Psychology: Research and Practice 36, 4 (2005), 347-354. https://doi.org/10.1037/0735-7028.36.4.347

[86] Mihaela Sabin, Hala Alrumaih, and John Imipagliazzo. 2018. A Competencybased Approach toward Curricular Guidelines for Information Technology Education. In 2018 Global Engineering Education Conference. IEEE, Tenerife, 1214-1221. https://doi.org/10.1109/EDUCON.2018.8363368

[87] Mihaela Sabin, Svetlana Peltsverger, Bill Paterson, Ming Zhang, and Hala Alrumaih. 2017. IT2017 Report: Putting It to Work. In Proceedings of the 18th Annual Conference on Information Technology Education (SIGITE '17). ACM, New York, NY, USA, 95-96. https://doi.org/10.1145/3125659.3125672

[88] Minna Salminen-Karlsson. 2011. The problem in the eye of the beholder: Working with gender reforms in computer engineering. International fournal of Gender, Science and Technology 3, 2 (July 2011), 445-459. http://genderandset. open.ac.uk/index.php/genderandset/article/view/164

[89] Deborah L. Schussler. 2006. Defining Dispositions: Wading Through Murky Waters. The Teacher Educator 41, 4 (March 2006), 251-268. https://doi.org/10. 1080/08878730609555387

[90] Phil Scott, Hilary Asoko, and J. Leach. 2007. Student Conceptions and Conceptual Learning in Science. In Handbook of Research on Science Education, Sandra K. Abell and Norman G. Lederman (Eds.). Routledge, New York, NY, USA, 31-56.

[91] Miguel-Angel Sicilia. 2010. How Should Transversal Competence Be Introduced In Computing Education? SIGCSE Bull. 41, 4 (Jan. 2010), 95-98. https://doi.org/ $10.1145 / 1709424.1709455$

[92] IEEE Computer Society. 2014. Software Engineering Competency Model (SWECOM). Technical Report Version 1.0. IEEE-CS. https://www.computer.org/web/ peb/swecom

[93] Brian M. Stack and Jonathan G. Vander Els. 2017. Breaking With Tradition :The Shift to Competency-Based Learning in PLCs at Work (Why You Should Switch to Student-Centered Learning for All). Solution Tree Press, Bloomington, IN. https://www.solutiontree.com/breaking-with-tradition.html

[94] NGSS Lead States. 2013. Next generation science standards: For states, by states. The National Academies Press, Washington, DC.

[95] Angela Stoof, Rob L Martens, and Jeroen JG Van Merriënboer. 2000. What is competence? A constructivist approach as a way out of confusion. Onderwijs Research Dagen (ORD), Leiden, The Netherlands (2000).

[96] Task Group on Information Technology Curricula. 2017. Information Technology Curricula 2017: Curriculum Guidelines for Baccalaureate Degree Programs in Information Technology. Association for Computing Machinery and IEEE Computer Society. https://doi.org/10.1145/3173161

[97] Juan Carlos Tedesco, Renato Opertti, and Massimo Amadio. 2013. The Curriculum Debate: Why It Is Important Today. IBE Working Papers on Curriculum Issues No. 10. UNESCO International Bureau of Education, Paris, France.

[98] Matti Tedre and Erkki Sutinen. 2008. Three traditions of computing: what educators should know. Computer Science Education 18, 3 (Sept. 2008), 153-170. https://doi.org/10.1080/08993400802332332

[99] European Parliament and the Council of European Union. 2006. Recommendations of the European Parliament and of the Council of 18 December 2006 of Key Competences for Lifelong Learning. Technical Report Doc. 2006/962/EC. European Union, Brussels.

[100] Neena Thota, Anders Berglund, and Tony Clear. 2012. Illustration of paradigm pluralism in computing education research. Australian Computer Science Communications 34,2 (2012), 103-112.

[101] Heikki Topi. 2017. Information Systems in CC2020: Comparing Key Structural Elements of Curriculum Recommendations in Computing. In 2017 Proceedings of SIGED: IAIM Conference. Association for Information Systems Electronic Library (AISeL). http://aisel.aisnet.org/siged2017/9

[102] J. Trevelyan. 2012. Understandings of value in engineering practice. In Proceedings of the 42nd Annual ASEE/IEEE Frontiers in Education Conference. IEEE, Seattle, WA, USA, 1-6. https://doi.org/10.1109/FIE.2012.6462258

[103] Marcel Van der Klink and Jo Boon. 2002. The investigation of competencies within professional domains. Human Resource Development International 5, 4 (2002), 411-424.

[104] Marcel Van der Klink, Jo Boon, and Kathleen Schlusmans. 2007. Competences and Vocational Higher Education: Now and in Future. European journal of vocational training 40, 1 (2007), 67-82.

[105] Richard A. Voorhees. 2001. Competency-Based Learning Models: A Necessary Future. New Directions for Institutional Research 2001, 110 (2001), 5-13. https: //doi.org/10.1002/ir.7

[106] Franz Emanuel Weinert. 2001. Concept of competence: A conceptual clarification. In Defining and selecting key competencies, Dominique Simone Rychen and 
Laura Hersh Salganik (Eds.). Hogrefe \& Huber, Seattle, WA, 45-65.

[107] Wim Westera. 2001. Competences in education: A confusion of tongues. Journal of Curriculum Studies 33, 1 (2001), 75-88. https://doi.org/10.1080 00220270120625 arXiv:https://doi.org/10.1080/00220270120625

[108] Jonathan Winterton, Françoise Delamare-Le Deist, and Emma Stringfellow. 2006. Typology of knowledge, skills and competences: clarification of the concept and prototype. Office for Official Publications of the European Communities,
Luxembourg. OCLC: ocm71257428.

[109] Charles Woodruffe. 1991. Competent by any other name. Personnel Management 23, 9 (1991), 30-33.

[110] David Scott Yeager and Carol S Dweck. 2012. Mindsets that promote resilience: When students believe that personal characteristics can be developed. Educational psychologist 47, 4 (2012), 302-314. 